Issued by Sandia National Laboratories, operated for the United States Department of Energy by Sandia Corporation.

NOTICE: This report was prepared as an account of work sponsored by an agency of the United States Government. Neither the United States Government, nor any agency thereof, nor any of their employees, nor any of their contractors, subcontractors, or their employees, make any warranty, express or implied, or assume any legal liability or responsibility for the accuracy, completeness, or usefulness of any information, apparatus, product, or process disclosed, or represent that its use would not infringe privately owned rights. Reference herein to any specific commercial product, process, or service by trade name, trademark, manufacturer, or otherwise, does not necessarily constitute or imply its endorsement, recommendation, or favoring by the United States Government, any agency thereof, or any of their contractors or subcontractors. The views and opinions expressed herein do not necessarily state or reflect those of the United States Government, any agency thereof, or any of their contractors.

Printed in the United States of America. This report has been reproduced directly from the best available copy.

Available to DOE and DOE contractors from

U.S. Department of Energy

Office of Scientific and Technical Information

P.O. Box 62

Oak Ridge, TN 37831

Telephone: (865)576-8401

Facsimile: (865)576-5728

E-Mail: reports@adonis.osti.gov

Online ordering: http://www.doe.gov/bridge

Available to the public from

U.S. Department of Commerce

National Technical Information Service

5285 Port Royal Rd

Springfield, VA 22161

Telephone: (800)553-6847

Facsimile: (703)605-6900

E-Mail: orders@ntis.fedworld.gov

Online order: http://www.ntis.gov/ordering.htm

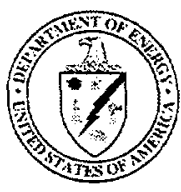




\section{DISCLAIMER}

Portions of this document may be illegible in electronic image products. Images are produced from the best available original document. 
SAND2000-1679

Unlimited release

Printed July 2000

\title{
INSULATED DRILL PIPE FOR HIGH-TEMPERATURE DRILLING
}

\author{
John Finger, Ron Jacobson, and Gary Whitlow \\ Geothermal Research Department \\ Sandia National Laboratories \\ Albuquerque, NM 87185-1033 \\ Tom Champness \\ Drill Cool Systems \\ 627 Williams Street \\ Bakersfield, CA 93305
}

\begin{abstract}
This report describes the work done to analyze and test insulated drill pipe (IDP), which can reduce downhole temperatures while drilling geothermal wells or other holes in hot formations. Cooler drilling conditions will preserve the drilling fluid, enhance bit life, reduce corrosion, and permit the use of downhole drilling motors, tools, and electronic instrumentation which are now unusable in geothermal wells because of high temperature. Development of IDP has comprised thermal and mechanical analysis, laboratory testing of prototype pipe, and a field test in a geothermal well.
\end{abstract}




\section{CONTENTS}

I. Introduction and Background ....................................... 1

II. Thermal Analysis ….................................................. 3

III. Mechanical Analysis and Pressure Test ............................ 5

IV. Thermal Test _............................................................ 17

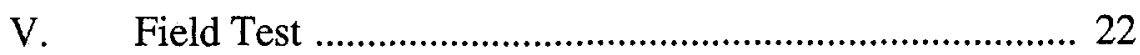

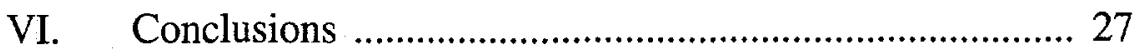

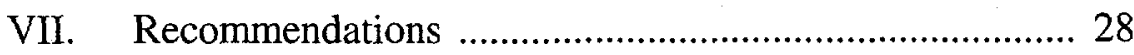

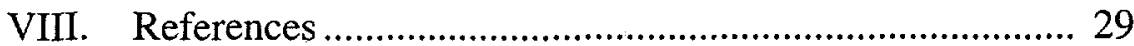




\section{Introduction and Background}

This project is directed at a fundamental problem - the damaging effect of high formation temperature on drilling tools, materials, and processes in geothermal wells. When drilling fluid gets too hot, it can irreversibly deteriorate in its ability to carry the drilled cuttings, can increase drill pipe corrosion by orders of magnitude, can shorten the life of bits and other downhole tools, can prevent the use of downhole motors and electronic instrumentation/tools, and can even affect borehole stability and well control. Each of these problems can be attacked by individual technology developments, but all of them can be solved or greatly mitigated by simply cooling the downhole environment with insulated drill pipe (IDP), which delivers drilling fluid to the bottom of the hole at a much lower temperature than conventional drill pipe (CDP).

Of the potential problems listed above, usually the most significant is the inability to use downhole motors and instrumentation. Because geothermal reservoirs usually have vertical or high-angle fractures, the greatest productivity is gained by directionally drilling along a trajectory to intercept the maximum possible number of fractures. This can be done with conventional rotary drilling, but orienting and maintaining the hole trajectory is very time-consuming and the typical hard, abrasive formations in geothermal reservoirs cause accelerated drill pipe wear when the pipe is rotated in a deviated hole. If cooler drilling fluid in the wellbore environment will allow the use of downhole motors (which turn the bit without rotating the drill string) and electronic steering/survey tools, then reservoir productivity can be maximized at minimum drilling cost.

Conventional rotary drilling uses steel drill pipe with drilling fluid circulating down the pipe, passing through the bit to clean the hole-bottom, and returning up the annulus between the pipe and borehole. Because the drill pipe is an effective counter-flow heat exchanger, drilling fluid temperatures inside and outside the pipe are very similar to each other at any given depth (see Figure 1 - the left-hand side of each curve is temperature inside the drill pipe and the right-hand side is temperature in the annulus between the drill pipe and wellbore). Fluid temperatures also tend to follow the formation temperature. In a given formation, downhole temperatures are affected by many drilling parameters - fluid flow rate, rate of penetration, fluid properties, bit-jet sizes, and the like - but sensitivity studies have shown that these factors are minor in comparison to the thermal conductivity of the drill pipe. Figure 1 shows the temperature reduction with IDP compared to conventional drill pipe in a 10,000 foot geothermal well, assuming that water is circulated at a rate of $500 \mathrm{gpm}$. These temperatures are calculated with the GEOTEMP2 thermal simulator ${ }^{1}$.

Several important aspects of this scenario are illustrated by the figure.

- Bottom-hole temperature is reduced from $401^{\circ} \mathrm{F}$ with CDP to $166^{\circ} \mathrm{F}$ with IDP. This is the temperature that downhole motors, steering tools, or measurementwhile-drilling (MWD) instrumentation must survive. It is important to note that the bottom-hole cannot be effectively cooled by only lowering the mud inflow 
temperature; in the situation illustrated by Figure 1, for example, lowering the inflow temperature by $40^{\circ} \mathrm{F}$ only lowers the bottom-hole temperature by $25^{\circ} \mathrm{F}$.

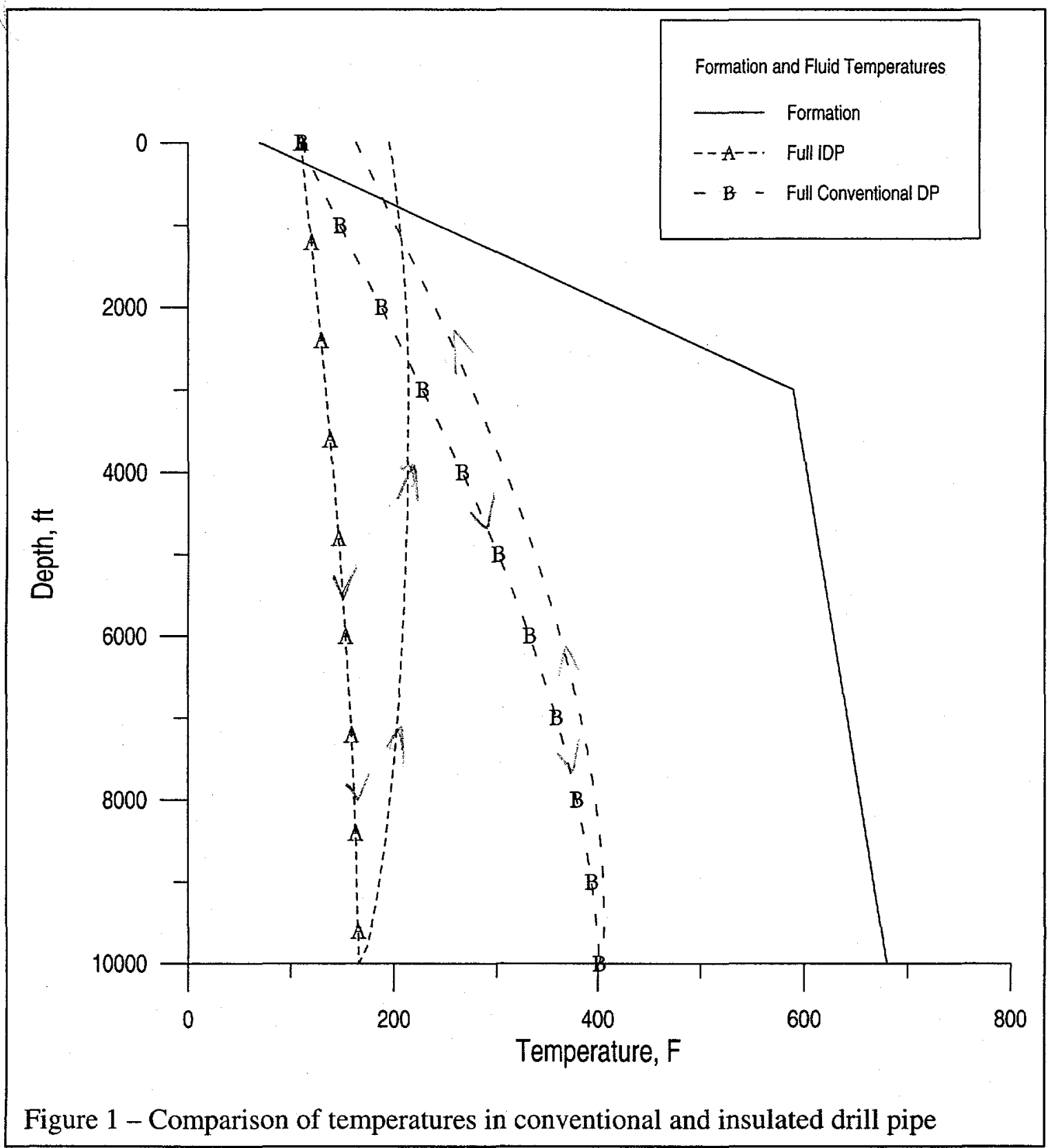

- Maximum fluid temperatures, which are not at the bottom of the hole, are $406^{\circ} \mathrm{F}$ for CDP and 214 $\mathrm{F}$ for IDP. For drilling fluid additives that degrade at high temperature, this difference can be critical.

- Fluid return temperatures are $163^{\circ} \mathrm{F}$ for CDP and $196^{\circ} \mathrm{F}$ for IDP. Although this may mean that surface mud coolers will be required with IDP, it also indicates that more heat is being removed from the wellbore, and therefore formation temperatures will be lower after drilling with IDP. This will be highly beneficial for cementing casing. 
Development of IDP, therefore, will further Sandia's goal of reducing the cost to drill and complete geothermal wells.

Background: Insulated drill pipe has a long history. Sandia worked on this concept in the early 1980s for application to the Magma Energy Program. Thermal and mechanical analyses were done at Sandia 2,3,4. Contracts for feasibility studies and preliminary designs of double-wall IDP were placed with two companies experienced in manufacturing insulated tubing for steam injection. The California Energy Commission provided grant money for this project, but a state budget crisis forced them to rescind the award at about the same time the DOE ended the Magma Energy Program.

The concept lay dormant at Sandia since then, but recently Drill Cool Systems (DCS) of Bakersfield, CA, has become interested in pursuing IDP as a business line. They built three joints of prototype IDP, did preliminary tests to evaluate the effective thermal conductivity of the pipe, and ran these joints in field operations - drilling one well and working-over another. This effort led to a contract with the Geothermal Drilling Organization (GDO) for further analysis, fabrication, and testing of IDP, including the construction of a complete string of pipe which would be tested in field drilling.

\section{Thermal Analysis}

As shown in Figure 2, the general form of IDP is a piece of conventional drill pipe with a liner welded into it and insulating material in the annulus between the two tubes. This annulus is created by the configuration of conventional drill pipe, which is built by friction-welding tool joints onto a pipe body, with the joints having a smaller inside diameter than the body. This construction leaves an interval at each connection that has no insulation between the inside and outside of the pipe, but the effect of this is analyzed below.

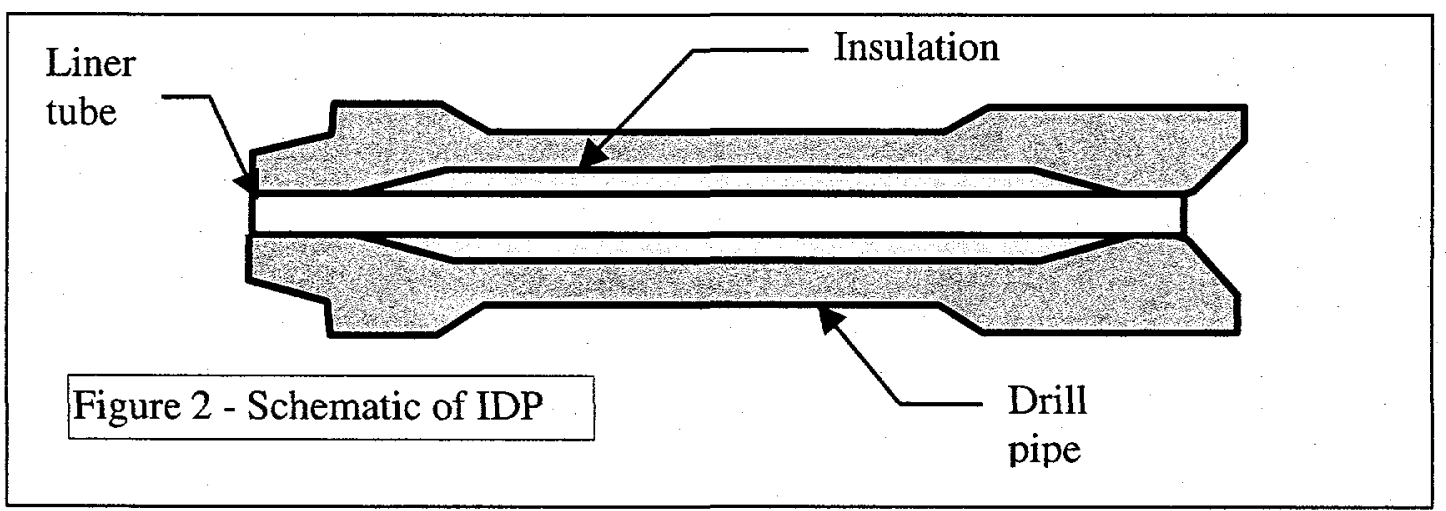

For a unit length of IDP, the heat transfer, $q$, is calculated using the standard equation: 


$$
q=2 \pi \Delta T\left[\frac{1}{\frac{1}{h_{4} r_{4}}+\frac{\ln \left(r_{4} / r_{3}\right)}{k_{\text {steel }}}+\frac{\ln \left(r_{3} / r_{2}\right)}{k_{\text {insulation }}}+\frac{\ln \left(r_{2} / r_{1}\right)}{k_{\text {steel }}}+\frac{1}{h_{1} r_{1}}}\right] \text {, }
$$

where $r=$ pipe radius, $k=$ thermal conductivity, $h=$ convective heat transfer coefficient, and the subscripts refer to the pipe radii as shown in Figure 3. For conditions (radii, flow

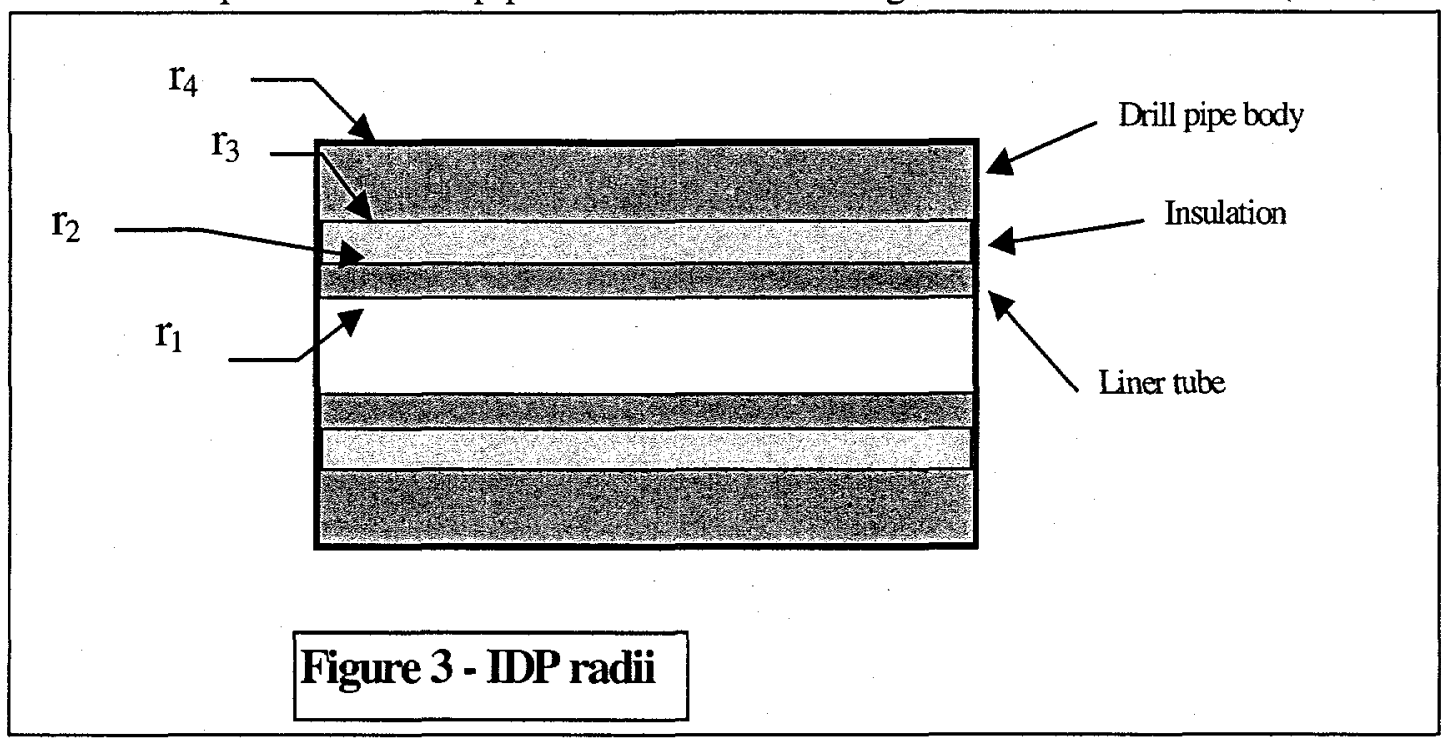

rates, fluid properties) typical of drilling, four of the five terms in the denominator of this equation are numerically of similar magnitude. Only the third term, which represents the low-conductivity insulation, is much larger than the others; e.g., using a conductivity value of $0.3 \mathrm{~B} / \mathrm{hr}-\mathrm{ft}-\mathrm{F}$ (where $\mathrm{B}=\mathrm{British}$ Thermal Unit) for the insulation gives a third term equal to $0.655 \mathrm{hr}-\mathrm{ft}-\mathrm{F} / \mathrm{B}$, while the sum of the other four terms is $0.019 \mathrm{hr}-\mathrm{ft}-\mathrm{F} / \mathrm{B}$. This means that for solid steel pipe the convective and conductive terms are relatively equal in importance, while the insulation dominates the total heat transfer for insulated pipe. A less-obvious consequence of this is that even a small amount of insulation has a significant effect on heat transfer; in other words, the insulation doesn't have to be extremely efficient.

Another limit on minimum heat transfer is set by the uninsulated tool joints at each end of each piece of pipe (Figure 2), which would conduct heat even if insulation in the pipe body were perfect. In considering possible insulation materials, there are many kinds of plastic, glass, or rock that have conductivity, or $k$, values from 0.1 to $0.5 \mathrm{~B} / \mathrm{hr}-\mathrm{ft}-\mathrm{F}$, compared to steel at 26 or good insulators such as cork at 0.025 or glass wool at 0.022 $\mathrm{B} / \mathrm{hr}-\mathrm{ft}-\mathrm{F}$, so a key question is to determine what range of $k$ value is necessary. In evaluating insulation requirements, however, calculated drilling fluid temperatures (including the effect of the tool joints) show that there is little difference in performance among IDPs with an insulating layer having conductivity values of $0.05,0.3$, and 1.0 $\mathrm{B} / \mathrm{hr}-\mathrm{ft}-\mathrm{F}$ (Figure 4). These cases are compared to conventional drill pipe in the same formation temperature profile as in Figure 1. Based on these considerations, dry sand 
with a $k$ value of approximately $0.25 \mathrm{~B} / \mathrm{hr}-\mathrm{ft}-\mathrm{F}$ was used for the insulation in the first prototype IDP.

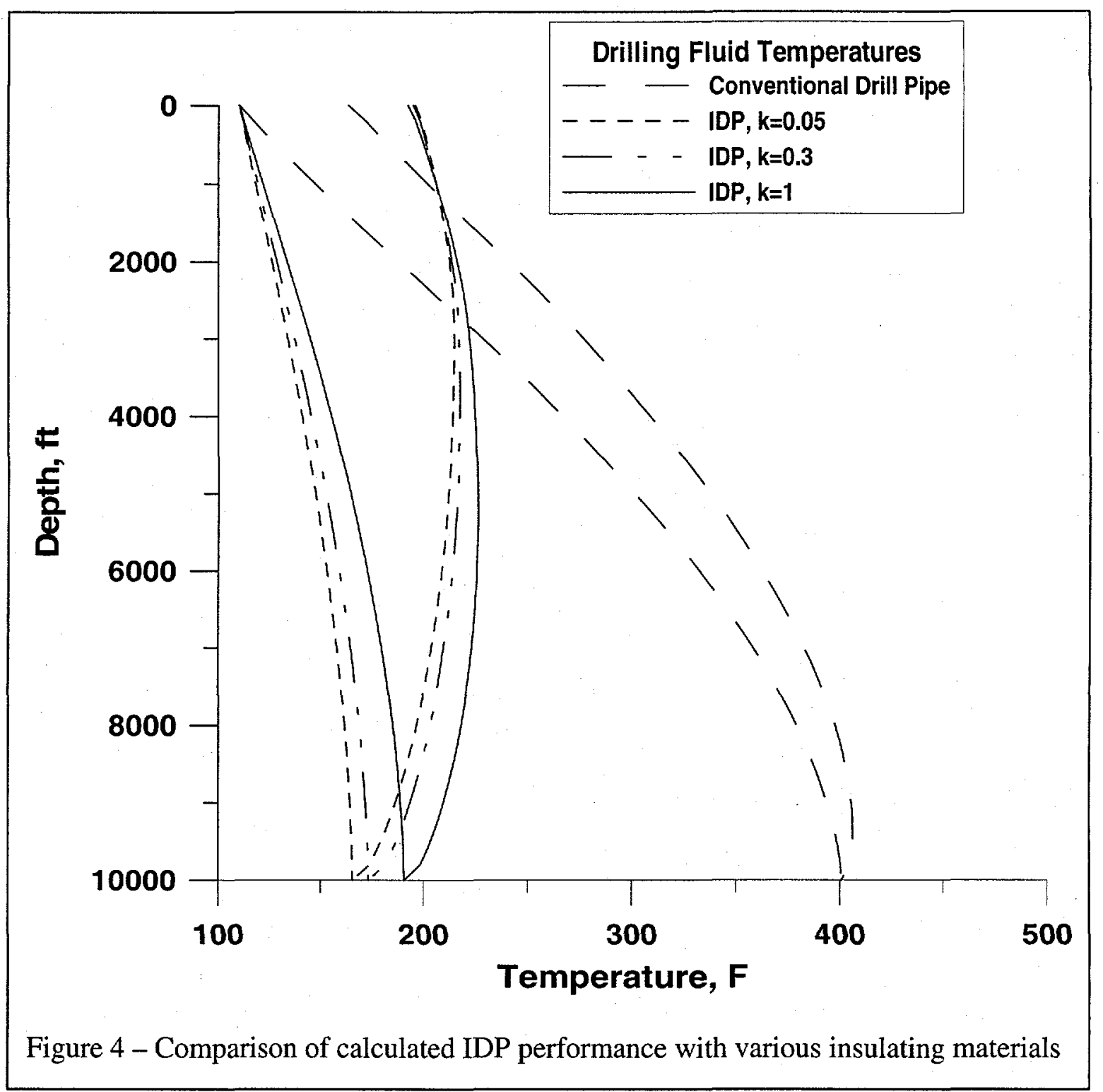

\section{Mechanical Analysis and Pressure Test}

Adding the liner tube and insulating material to standard drill pipe will affect stresses in the pipe in the following three ways:

- Axial stress - The liner tube will add weight, but will also add axial strength in the same proportion as the weight, while the insulation's weight is small compared to the steel tubes. If we assume no pre-load in either tube, then axial strain and stress will be the same in both tubes. If the liner tube's yield strength is equal to that of the drill pipe, then depth limits because of pipe weight will be 
only slightly smaller than for conventional drill pipe. (There may, however, be a significant problem if the extra string weight exceeds the drill rig capacity.)

- Bending stress - Addition of a liner tube will increase the moment of inertia of the IDP's cross-section, compared to CDP, which increases stiffness both in bending and in torsion. For typical dimensions such as those used in earlier calculations, the increase in stiffness is about $20 \%$.

- Hoop stress - The liner tube will be subjected to hoop stress because of internal pressure from fluid in the pipe. If the insulation is in good contact with the outside of the liner tube and inside of the drill pipe, however, some of the hoop load will be transferred by the insulation from the liner to the pipe. This effect is analyzed in more detail below.

Hoop stress support: Take a force balance on a cross section of IDP as shown in Figure 5, with $P_{t}$ and $P_{i}$ equal to the test pressure and the pressure transmitted by the insulation, respectively, and $\sigma_{\mathrm{L}}$ and $\sigma_{\mathrm{P}}$ equal to the hoop stresses in the liner tube and drill pipe, respectively. Then, for drill pipe with $\mathrm{ID} / \mathrm{OD}=4.276 " / 5 "$ and liner tube with $\mathrm{ID} / \mathrm{OD}=$ 3.068"/3.5",

(2) $(5-4.276) \sigma_{P}=4.276 P_{i}$ in the drill pipe, and

(3) $(3.5-3.068) \sigma_{L}+3.5 P_{i}=3.068 P_{t}$ in the liner tube.

Assuming then that the insulation acts as a perfect fluid, transmitting pressure uniformly without compressibility, the change in volume of the liner tube's outer surface will be equal to the change in volume of the drill pipe's inner surface. Expressing each volume change in terms of the pressures causing it, and equating the changes, gives the relation

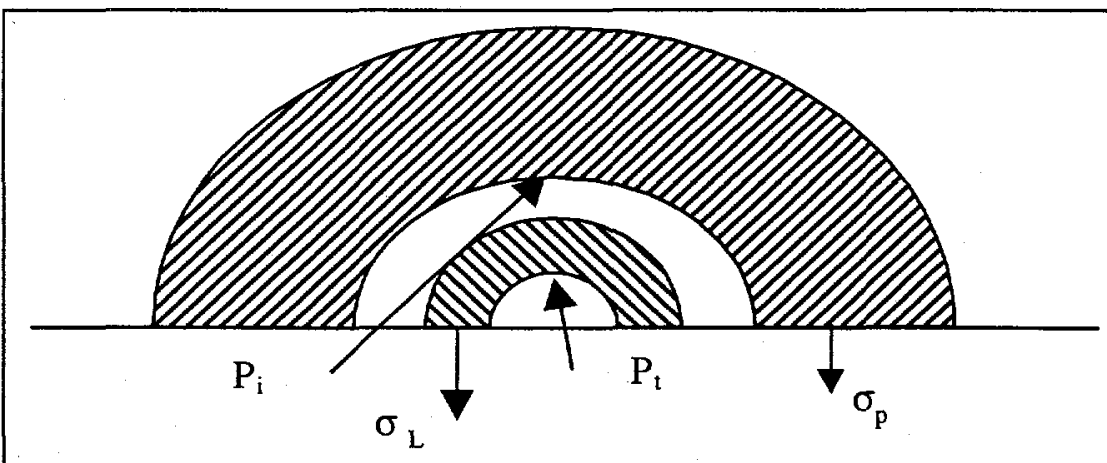

Figure 5 - Cross section of stress and pressure in IDP

(4) $P_{i}=0.42 P_{1}$. Combining Eq (4) with Eq (3) gives

(5) $\sigma_{L}=3.70 P_{t}$.

If no support from the insulation is assumed, then $P_{i}$ goes to zero in $\mathrm{Eq}(3)$ and

(6) $\sigma_{L}=7.1 P_{\imath}$.

That is, if the insulation provides effective support, it almost doubles the internal pressure capability of the liner tube. This is important because it means that the liner can be made 
of thinner material that does not need to withstand the full internal pressure due to static head and pumping.

To evaluate this analysis in the laboratory, a series of pressure tests on strain-gauged IDP was done at Drill Cool System's shop in Bakersfield, California. Each piece of IDP was a joint of conventional 5", $19.5 \mathrm{lb} / \mathrm{ft}$ grade G-105 drill pipe with a liner made of 3.5" OD by 3" ID, grade L-80 tubing. The drill pipe is approximately 30 feet long and has an inside diameter in the body of 4.276 inches. The annular volume between the tubes can be filled with various insulating materials, but the pipes in this test used proppants designed for holding open hydraulic fractures in rock formations.

Test assumptions and procedure: The principle of the test was to apply an internal pressure to the IDP while reading strain in hoop and axial directions with strain gages placed inside and outside the pipe (see Figure 6). Deflections of both the inner and outer tubes can be calculated based on the assumption of "perfect" support described above, and also from an assumption of no support.

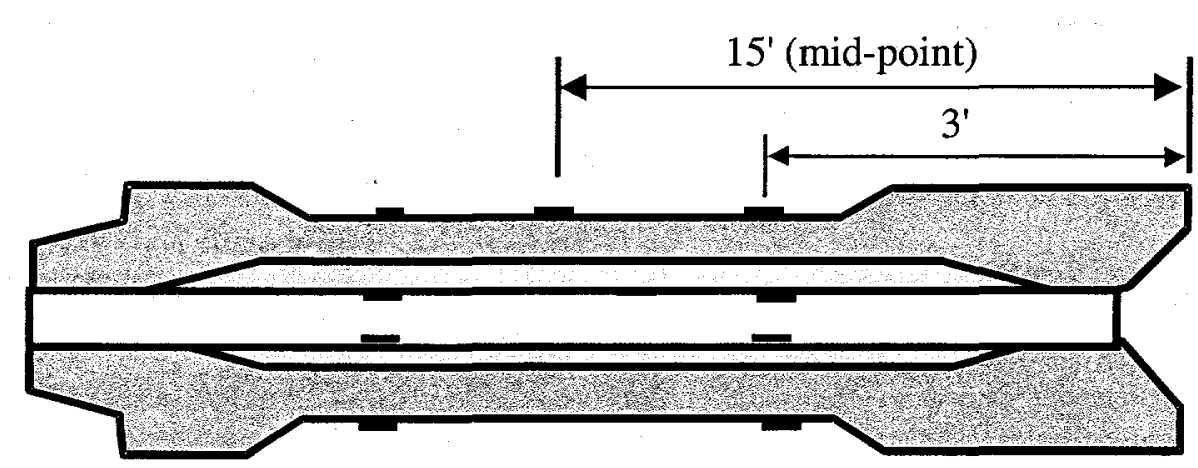

Figure 6 - Strain gage locations

Each of the two tested pipes was fitted with 9 bi-axial strain gages: two gages each inside and outside, oriented at $180^{\circ}$ from each other, $36^{\prime \prime}$ from each end of the pipe; plus one gage in the center of the pipe-body outside diameter. The inside and outside gage locations all lay (within $1 / 2$ " of each other) on a plane through the centerline of the pipe body. A pressure transducer was connected to the pump inlet line to monitor internal pressure; its output was compared during the test with a dial pressure gage at the inlet fitting, which showed good agreement.

Test results: After the internal gages were bonded into the first pipe, we ran the gage leads through its end caps, transported the pipe to a service company where the caps were tightened to $30,000 \mathrm{ft}-1 \mathrm{~b}$ (recommended make-up torque for this connection), returned the pipe to the DCS plant, and filled it with hydraulic oil. While the oil was being added to the pipe, we connected the wiring harness from the data system to the external gages and to the electrical feedthroughs from the internal gages, and then, for safety, lowered the pipe into a cased 10" diameter hole approximately 40' deep. Two of the internal gages 
(one hoop, one axial) could not be zeroed, apparently as a result of being shorted to ground, but we elected to continue the test rather than wait 24 hours for replacement with another set of gages (which would also have no assurance of proper operation). When we applied pressure inside the pipe (approximately $5000 \mathrm{psi}$ ), all the external gages appeared to be working properly (i.e., the direction - tension - was correct). The internal gages, however, were extremely erratic, fluctuating from tension to compression at rapidly changing values. Some of the readings were consistent with a leak in the liner, which would pressurize the volume between the liner and pipe, and calculation of hoop stress in the outer pipe, assuming pressure in that annulus, gave a value consistent with the hoop strain readings in the external gages.

We checked the instrumentation system in several ways: connecting a strain-gage simulator to one of the suspect channels in the data system; reading one of the suspect gages with a portable strain reader instead of the data system; and re-zeroing all the settings with no pressure in the pipe. All of these tests indicated that the gage readings represented real physical phenomena but did not explain their somewhat erratic behavior.

We next pulled the pipe out of the hole, drained the oil, and disconnected the wiring bundle from the external gages. Each end of the pipe was supported on a steel rack and the pipe was loaded in bending, then turned over and loaded again with bending in the opposite direction (relative to the gages). In all cases the internal axial gages gave readings which were in the correct tension/compression direction, further verifying our assumption that the gages and data system were operating properly. Finally, DCS built a hydraulic-ram fixture to load the pipe in compression; this test condition not only showed compression on all three functional internal-axial gages, but the magnitude was approximately correct based on a load calculated from the ram piston diameter and pump pressure. In short, the data from the external gages appears to be reasonable and correct, based on a leak in the inner pipe letting pressure into the annulus, but the leaky annulus prevents a reliable distinction between gage behavior and true variation. The only factor that was not simulated in the static gage tests was the presence of hydraulic oil under pressure.

The second pipe, after having its welds checked for leaks, was instrumented in exactly the same way as the first pipe. This pipe was also pressurized, first with an electric pump and then, after the electric pump would not go above approximately 8500 psi, with a hand pump. The highest pressure during the test was just over 12,000 psi. Test data from the second pipe were more reasonable, but still contained apparent anomalies and inconsistent behavior. Again, the external gages showed results that compare reasonably well with calculated strains, but there was more fluctuation in the internal gages.

Axial strains in the inner and outer tubes should be equal, since they should lengthen the same amount for a given pressure, and hoop stresses in each pipe will vary with the amount of support which is transferred through the insulation. Using dimensions of the test pipes, calculated stresses in laboratory loading are the following: 
(7) $\sigma_{a x}=\frac{P_{t} 3.068^{2}}{5^{2}-4.276^{2}+3.5^{2}-3.068^{2}}=.985 P_{t}$,

(8) $\sigma_{i n-h p}=3.7 P_{t}$, (from Eq 5), $\sigma_{e x-h p}=2.48 P_{t}$ for perfect insulation support,

and

(9) $\sigma_{i n-h p}=7.1 P_{t}$, (from Eq 6), $\sigma_{e x-h p}=0$ with no insulation support.

In Eqs 7-9, $\sigma_{a x}=$ axial stress, $\sigma_{i n-h p}=$ hoop stress in the liner tube, and $\sigma_{e x-h p}=$ hoop stress in the drill pipe.

In a general 3-dimensional stress state, strain is affected not only by stress in the direction in which it is being measured, but also by the Poisson effect of perpendicular stresses. For $\mathrm{x}-\mathrm{y}-\mathrm{z}$ coordinates,

(10) $\varepsilon_{x}=\frac{1}{E}\left[\sigma_{x}-\mu\left(\sigma_{y}+\sigma_{z}\right)\right]$, where $\mathrm{E}$ is the elastic modulus and $\mu$ is Poisson's ratio.

Interpretation of measured strain values (hoop, axial) must include the Poisson effects and the gage correction due to internal pressure $(-7$ microinches/inch/1000 psi).

Expected strains expressed in terms of test pressure and the dimensions of the pipe are then the following, given in units of microinches/inch. (Assume Poisson's ratio $=0.3$, there is no pressure term for the outer pipe, and the sign convention is that tensile strains are positive and compressive strains are negative.)

Perfect support:

(11) $\varepsilon_{e x-a x}=\frac{\left[\sigma_{a x}-0.3\left(\sigma_{e x-h p}\right)\right]}{E}=\frac{0.24 P}{30} \mu \mathrm{in} / \mathrm{in}$

(12)

$\varepsilon_{i n-a x}=\frac{\left[\sigma_{a x}-0.3\left(\sigma_{i n-h p}-P\right)\right]}{E}-.007 P=\frac{.175 P}{30}-.007 P=-.0012 P$

(13) $\varepsilon_{e x-h p}=\frac{\left[\sigma_{e x-h p}-0.3\left(\sigma_{a x}\right)\right]}{E}=\frac{2.18 P}{30}$

(14) $\varepsilon_{i n-h p}=\frac{\left[\sigma_{i n-h p}-0.3\left(\sigma_{a x}-P\right)\right]}{E}-.007 P=\frac{3.705 P}{30}-.007 P=.117 P$ 
No support:

(15) $\varepsilon_{e x-a x}=\frac{\left[\sigma_{a x}\right]}{E}=\frac{0.985 P}{30} \mu \mathrm{in} / \mathrm{in}$

(16) $\varepsilon_{\text {in-ax }}=\frac{\left[\sigma_{a x}-0.3\left(\sigma_{i n-h p}-P\right)\right]}{E}-.007 P=\frac{-.845 P}{30}-.007 P=-.035 P$

(17) $\varepsilon_{e x-h p}=\frac{\left[\sigma_{e x-h p}-0.3\left(\sigma_{a x}\right)\right]}{E}=\frac{-.296 P}{30}$

$\varepsilon_{i n-h p}=\frac{\left[\sigma_{i n-h p}-0.3\left(\sigma_{a x}-P\right)\right]}{E}-.007 P=\frac{7.105 P}{30}-.007 P=.230 P$

The strain readings from the gages are compared to calculated values in figures $7-10$.

Discussion of results: Internal hoop gages (Figure 7): All gages start relatively close to the "no support" line, and the A and B gages stay with that line up to a pressure of approximately $9-10,000 \mathrm{psi}$. At this same point, which is reasonably close to the 10,900 psi pressure calculated to produce yield with no insulation support, the $\mathrm{C}$ gage suddenly falls to a much lower value. It is probable that the inner tube yielded at this pressure, causing gage $\mathrm{C}$ to become either partially detached or otherwise non-functional, and causing the strain in gages $A$ and $B$ to exceed the elastic strain calculated with no support. This idea is supported by the large permanent strain seen in A and B when pressure is reduced back to zero.

Internal axial gages (Figure 8): Note that most of the strain here is compressive, which appears anomalous, but is caused by the Poisson effect of the much larger hoop strains at the same points. That is, the tension in the hoop direction causes a tendency for the strain to be compressive perpendicular to it, and this effect is larger than the tensile strain caused by the pipe's tendency to grow longer due to the internal pressure. Gage G shows erratic behavior, but this is the other half of gage $C$ in figure 7 , so it is consistent with that gage mounting becoming defective. Gages $\mathrm{F}$ and $\mathrm{H}$ generally show linear behavior in the region of calculated values, but it is not clear why they are so different.

External hoop gages (Figure 9): All these gages are reasonably consistent with the calculated "no support" line, although several of them tend to rise sharply at higher pressures. This could reasonably indicate that the insulation is taking more load as the inner tube expands and consolidates the silica particles. That assumption is also consistent with the hysteresis in the curves as pressure is applied and released to the pipe. That is, at equal pressures the strain is higher on the release cycle than on the pressurize cycle, which could be the result of more support from the insulation. Again, it is not clear why there are significant differences among these gages (which should theoretically read the same) unless the insulation beneath the gage locations is not uniformly packed, giving more support in some places than others. 


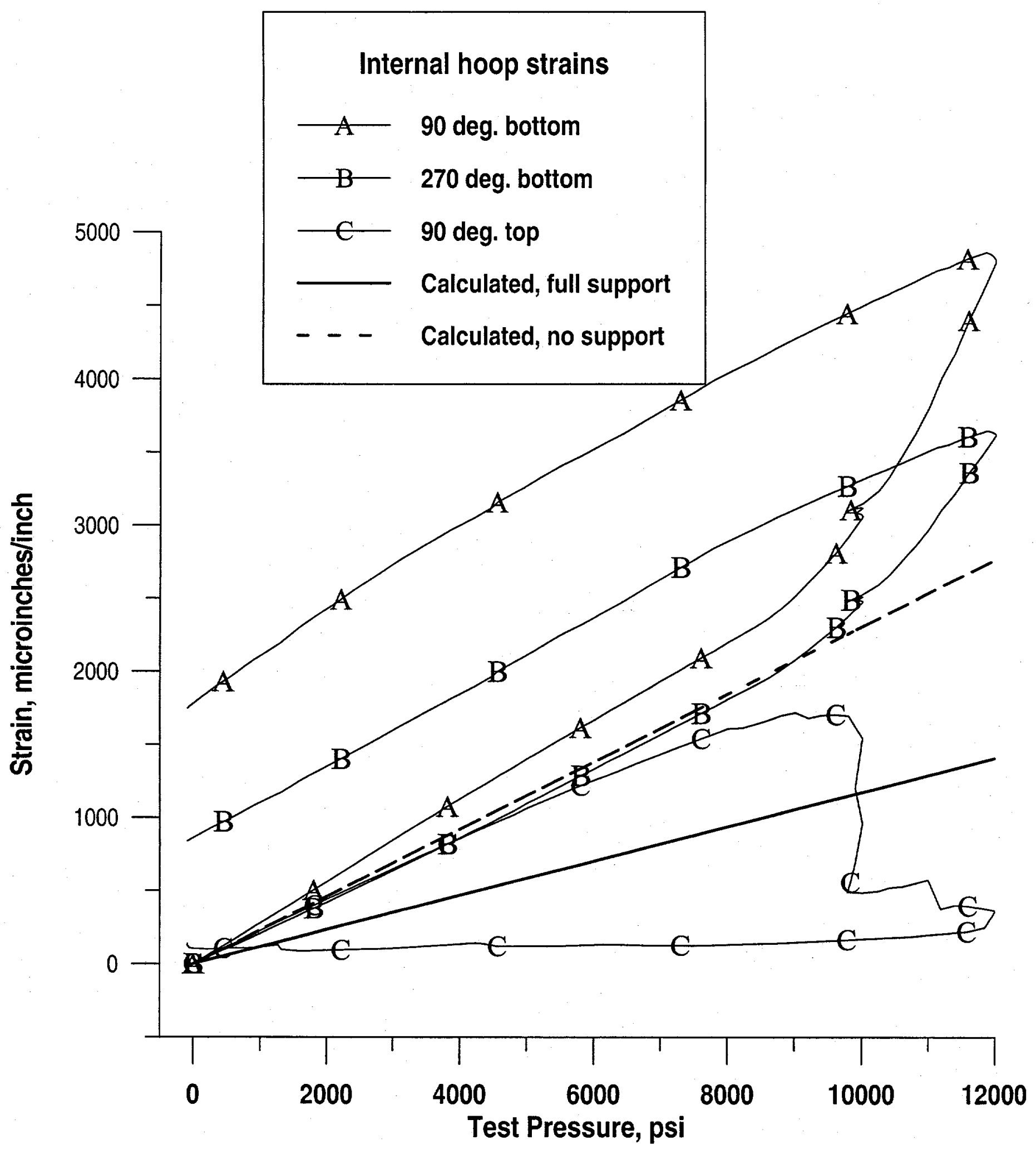

Figure 7 - Strains, internal hoop gages 


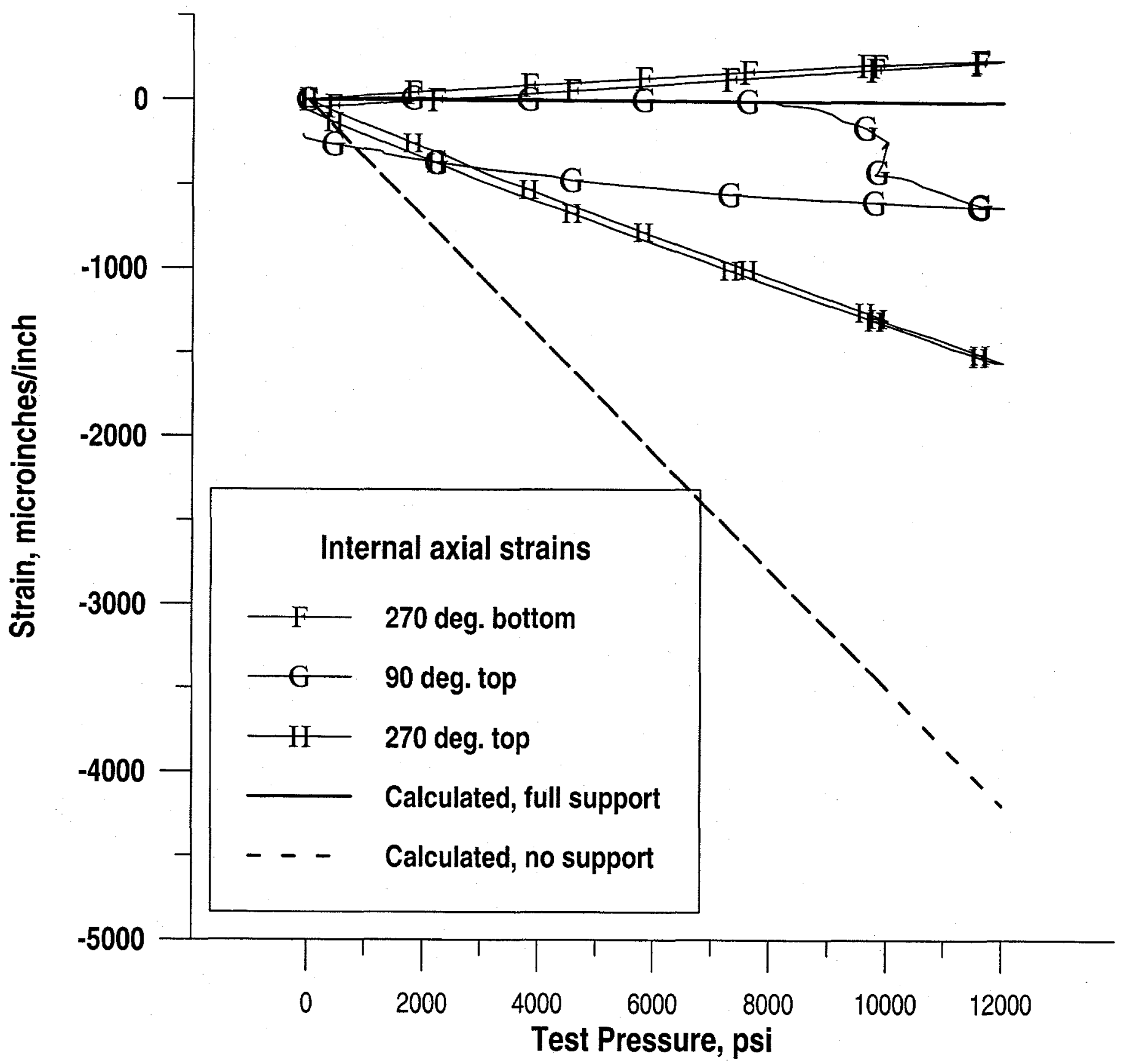

Figure 8 - Strains, internal axial gages 


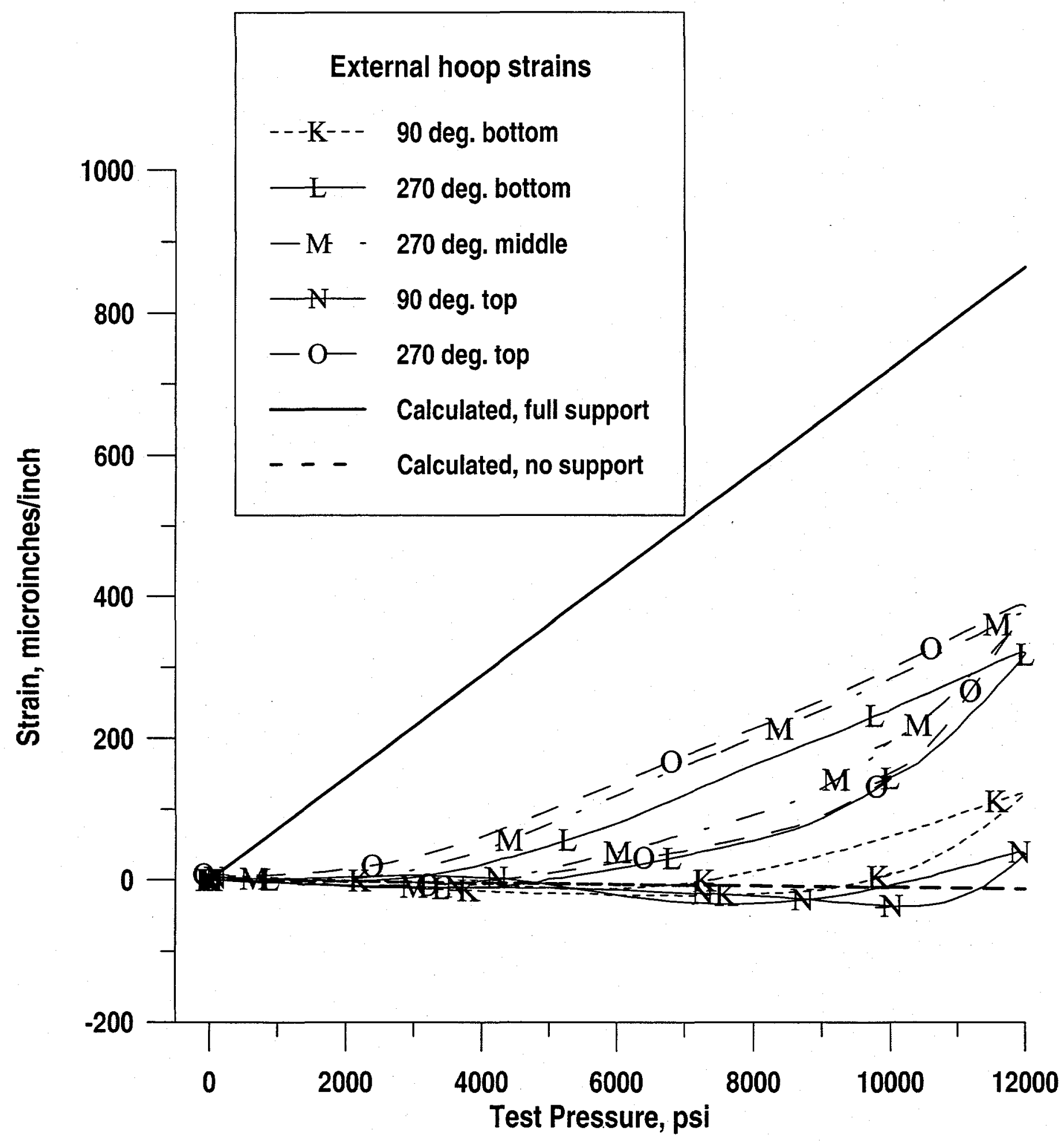

Figure 9 - Strains, external hoop gages 


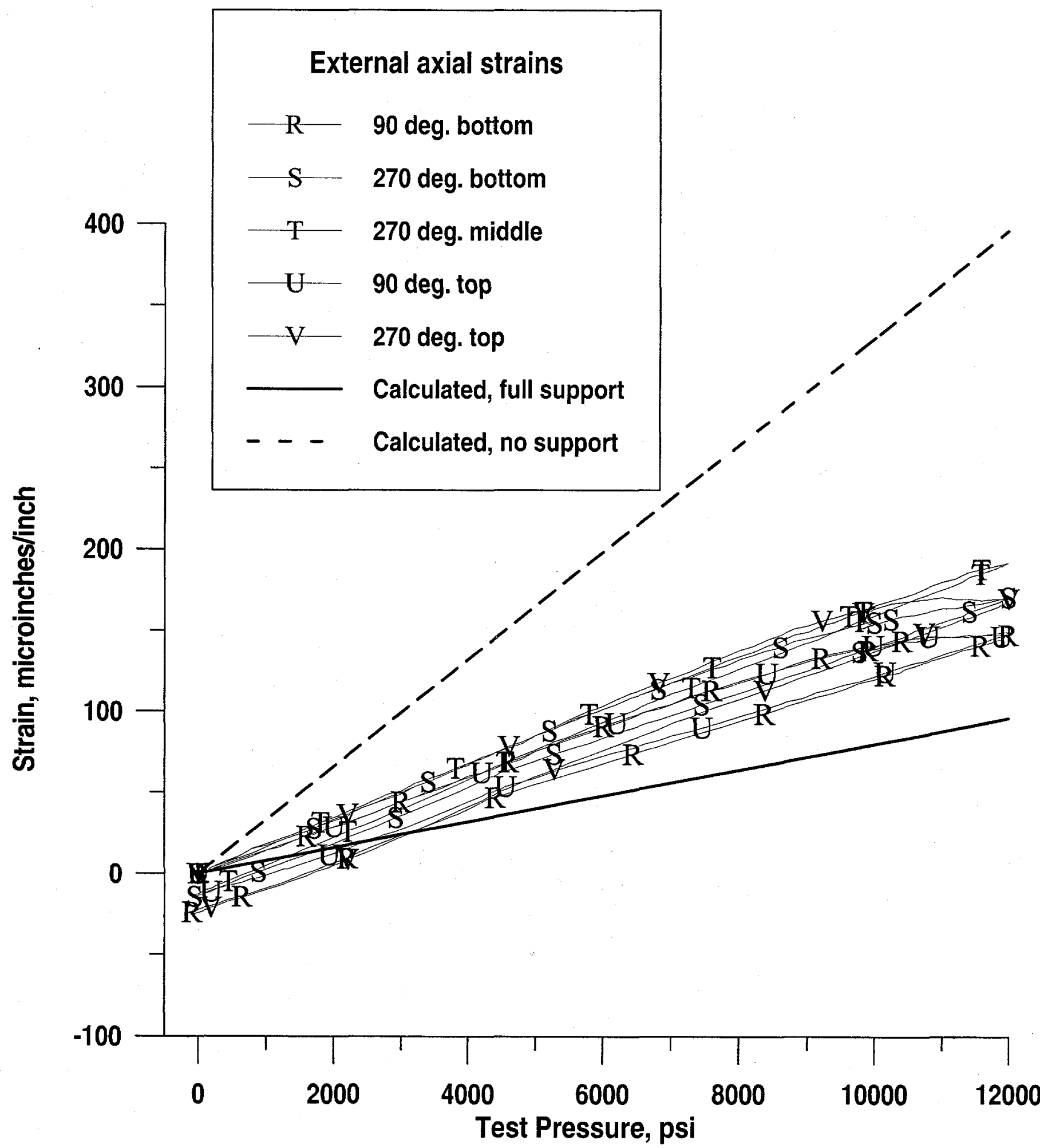

Figure 10 - Strains, external axial gages 
External axial gages (Figure 10): Data for the axial gages are generally consistent with the hoop gages; there is little variation among the five gages, and most of them tend to bend downward (toward the "full support" line) at higher pressure. Hysteresis in these curves is in the "correct" direction, with strains lower on the pressure release cycle. It is not clear why all these curves fall closer to the "full support" than the "no support" line.

Application of test results: In considering the depth limitations of IDP used in a well, there are two principal considerations: the weight of the pipe hanging in the hole creates a tensile load which defines a maximum depth which a uniform string of pipe can reach; and static head of drilling mud (plus pump pressure) inside the pipe approaches a limiting value of internal pressure that the liner pipe can withstand, assuming some amount of support from the insulating material in the annulus. The three principal stresses in the liner are $\sigma_{\mathrm{p}}=$ internal pressure, $\sigma_{\mathrm{a}}=$ axial, and $\sigma_{\mathrm{h}}=$ hoop stress. These stresses are given by the following equations:

$\sigma_{p}=P-(P-1000)\left(\frac{D}{L}\right)+.052 D M$

$$
\sigma_{a}=\frac{W(L-D)+\frac{\pi d_{l}^{2}}{4}\left[P-(P-1000)\left(\frac{D}{L}\right)\right]}{A}
$$

(21) $\sigma_{h}=R \sigma_{p}\left(\frac{d_{l}}{2 t_{l}}\right)$

where:

$R=$ relation between hoop stress and internal pressure $(1=$ no support, $0.52=$ full support),

$\mathrm{W}=$ pipe weight, pounds/foot,

$A=$ total cross-sectional area of both tubes, square inches,

$M=$ mud weight, pounds/gal,

$\mathrm{D}=$ distance from surface, feet,

$\mathrm{L}=$ length of drill pipe, feet,

$\mathrm{d}_{1}=$ inside diameter of liner, inches,

$\mathrm{t}_{1}=$ wall thickness of liner, inches, and

$\mathrm{P}=$ standpipe pressure (decreases from nominal value at the surface to $1000 \mathrm{psi}$ at the bit), pounds/square inch.

In a general condition of combined stress, the von Mises theory is that failure will not occur if:

$$
\sigma_{y p}>707 \sqrt{\left(\sigma_{1}-\sigma_{2}\right)^{2}+\left(\sigma_{2}-\sigma_{3}\right)^{2}+\left(\sigma_{3}-\sigma_{1}\right)^{2}}
$$

where $\sigma_{\mathrm{yp}}=$ tensile yield stress, and $\sigma_{1}>\sigma_{2}>\sigma_{3}$. 
Because the pipe-weight stress $\left(\sigma_{\mathrm{a}}\right)$ is greatest at the top of the pipe and the mud-pressure stress $\left(\sigma_{h}\right)$ is greatest at the bottom, their relative magnitudes (and order in the failure equation) will change. Calculating these relationships over the length of the drill pipe yields the results shown in Figure 11, where the test pipe dimensions, along with mud weight of $10 \mathrm{lb} / \mathrm{gal}$, pump pressure of $3000 \mathrm{psi}$, and pipe weight of $33 \mathrm{lb} / \mathrm{ft}$, are used in the calculations.

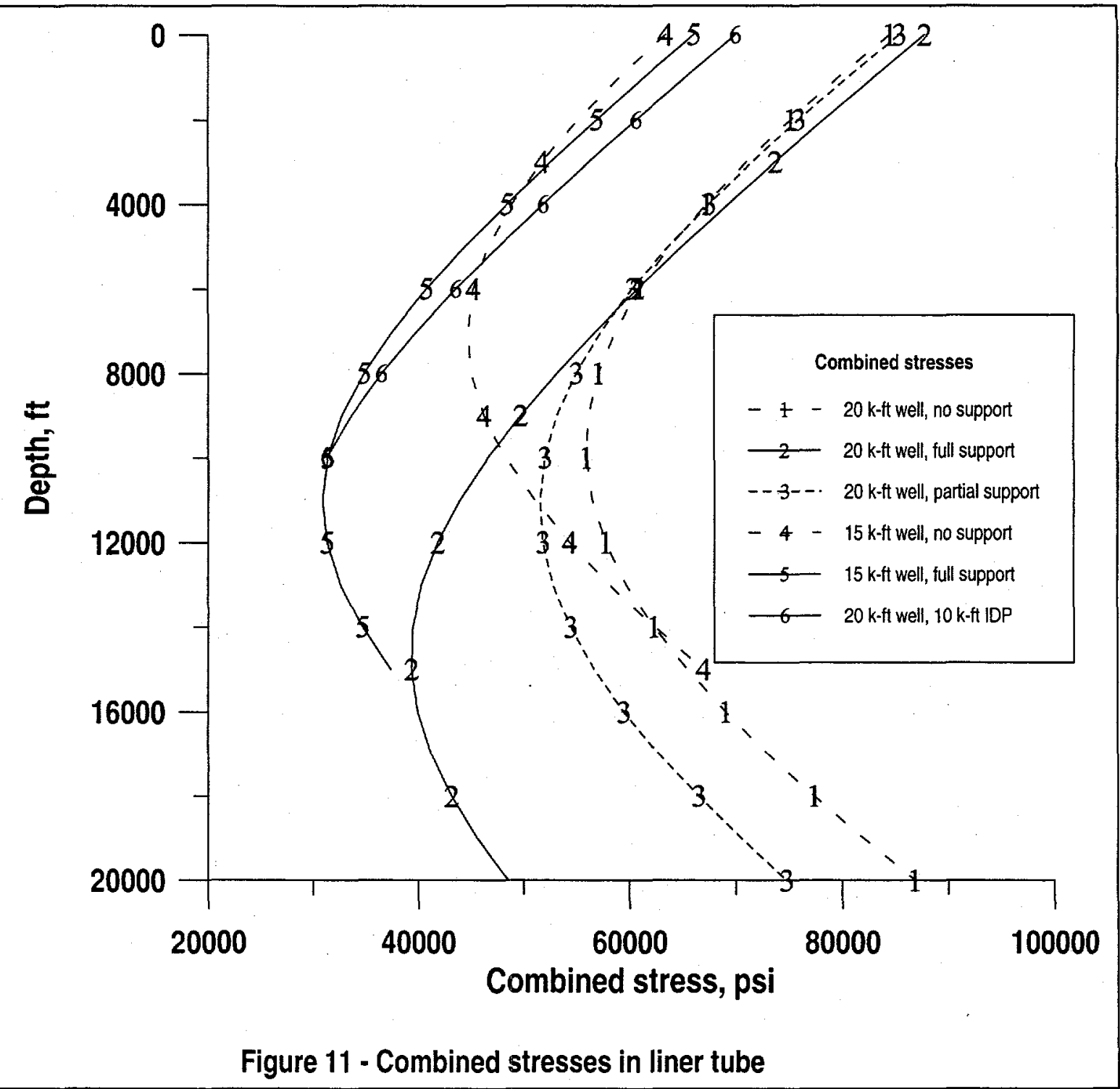

Assuming a material with 80,000 -psi yield is used for the liner tube, then that stress is exceeded both at the top and at the bottom of a 20,000 foot well, but for a 15,000 foot well, the stress is below yield even with no support from the insulation. There is considerable opportunity to manipulate other drilling parameters such as mud weight, mixed strings (not all IDP), and pump pressures to change the stress conditions for a given drilling scenario. As one example, curve 6 in Figure 11 shows the stresses in the top 10,000 feet of a mixed 20,000' string of pipe - the top 10,000' is IDP and the bottom 
half is normal $19.5 \mathrm{lb} / \mathrm{ft}$ drill pipe. By lowering the total weight of the drill string, axial and combined stresses at the top go below the tensile yield of the liner tube.

Note that the calculations for these cases are conservative, in that they are based on an empty wellbore annulus (no fluid). This means that axial stress at the top of the string is not reduced by buoyancy, and hoop stress at the bottom is not counter-acted by external pressure (assuming that external pressure can be transmitted through the insulation).

Conclusions: The data from the pressure test, although not as repeatable as might be expected, indicated clearly that the insulation did not provide significant support to the inner tube, at least at lower pressures. It appears, however, that once the inner tube has yielded and taken a permanent deformation, then it will receive more support on subsequent loading.

Calculated stress values did seem to be generally consistent with the data, leading to some confidence that we can predict behavior of the IDP in a field situation. Given these assumptions, it appears that IDP is already suitable for drilling 15,000-foot wells, and with alterations of the drillstring configuration (replacing some of the IDP with normal drill pipe for reduced weight) it can be used to depths of 20,000 feet.

\section{Thermal Test}

Sandia National Laboratories and Drill Cool Systems tested insulated drill pipe to measure the thermal conductivity of the pipe body and to assess the effect of un-insulated tool joints. The composite IDP, including the un-insulated joints, showed an effective conductivity that was less than $10 \%$ of conventional drill pipe.

The test procedure was to enclose a section of test pipe in a length of 9-5/8" casing, with separate supplies of water circulating through the test pipe and through the annulus between the IDP and the casing (see Figure 12). Test measurements were: cold water temperatures in and out, hot water temperatures in and out, hot and cold water flow rates, and pressure in hot and cold loops.

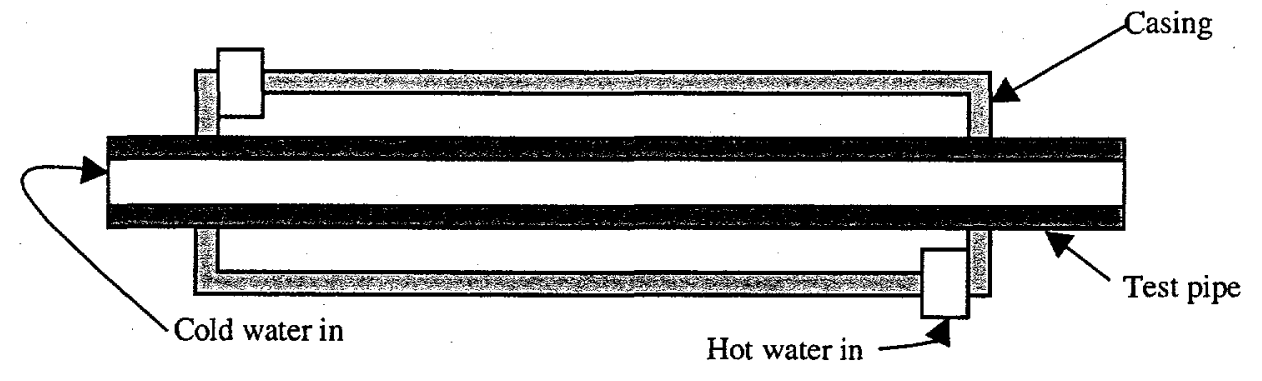

Figure 12 -- Schematic of thermal test set-up 
By measuring the temperature rise through the test pipe and calculating the total heat flow necessary for that increase, given the average temperature difference between the two water streams, the conductivity of the pipe wall could be evaluated. (The heat-gain in the pipe was checked by also calculating heat-loss from the annulus; this heat-loss should be slightly greater than the heat-gain in the pipe because the casing, even though insulated on the outside, was also losing heat to the atmosphere.) The standard equation for heat flow through the wall of a cylinder with fluid flow inside and outside is:

$$
\dot{q}=2 \pi L\left[\frac{\Delta T_{\text {avg }}}{\frac{1}{h_{i} r_{i}}+\frac{\ln \left(r_{o} / r_{i}\right)}{k_{\text {pipe }}}+\frac{1}{h_{o} r_{o}}}\right] \text {, }
$$

where $\Delta T_{\text {avg }}=$ difference in average temperatures between flow in pipe and flow in annulus,

$h_{i}, h_{o}=$ convective heat transfer coefficients inside and outside pipe, respectively, $\mathrm{L}=$ pipe length,

$r_{i}, r_{o}=$ inside and outside radius of pipe, respectively, and

$k_{\text {pipe }}=$ overall thermal conductivity of drill pipe wall.

Rearranging Eq 23 as shown below gives an expression in which all the terms on the right-hand side can be measured or evaluated from known quantities, and thus gives the cylinder's conductivity.

$$
k_{\text {pipe }}=\frac{\ln \left(r_{o} / r_{i}\right)}{\frac{2 \pi L \Delta T_{\text {avg }}}{\dot{q}}-\frac{1}{h_{i} r_{i}}-\frac{1}{h_{o} r_{o}}}, \text { and }
$$

(24a) $\dot{q}=(Q)\left(\Delta T_{\text {pipe }}\right)\left(c_{p}\right)\left(\rho_{\text {water }}\right)$, where $Q=$ flow rate of water through pipe.

The "test pipe" took three different configurations: (1) a straight section of conventional $5 ", 19.5 \mathrm{lb} / \mathrm{ft}$ drill pipe, (2) a straight section of double-walled, insulated pipe with 5 " OD and 3.068" ID, (3) a section of IDP with an uninsulated NC50 tool joint in the middle. This combination allowed us to compare the insulating value of the IDP with CDP, and then to evaluate the effect of introducing an uninsulated section into the drill string.

When CDP was tested in the first series, Equation 24 did not give conductivity for the steel pipe body that was near the commonly accepted value of about $25 \mathrm{~B} / \mathrm{hr}-\mathrm{ft}-\mathrm{F}$. When the numerical values of the quantities in the denominator of the equation are examined, however, it is clear that the first term is very close to the sum of the second and third terms (which are fairly close to each other), so that small changes in any of these will have a significant effect on the quotient. The least-well-known quantities in the equation 
are the convective heat transfer coefficients, $h$, which are calculated from the semiempirical expression:

$$
h=\frac{k}{D} .023 \operatorname{Re}^{0.8} \operatorname{Pr}^{0.4}
$$

where $\mathrm{k}=$ thermal conductivity of the water

$\mathrm{D}=$ inside diameter of the pipe, or hydraulic radius of the annulus,

$\mathrm{Re}=$ Reynolds number, and

Pr $=$ Prandtl number.

To assess the effect of uncertainty in calculating these convective coefficients, a "correction factor" for them was introduced into Eq 24 that would give conductivity for the steel pipe of $25 \mathrm{~B} / \mathrm{hr}-\mathrm{ft}-{ }^{\circ} \mathrm{F}$. This correction factor became closer to unity as the flow rates increased, ranging from 1.7 when both Reynolds numbers were below 20,000 to a minimum of 1.21 when both Reynolds numbers were above 30,000 (that is, the coefficients calculated from Eq 25 were increased by $21 \%$ to give the "correct" thermal conductivity for steel). It is possible that the correction factor could have become even smaller at still higher flow rates, but these were limited by the pump capacities.

When the conventional drill pipe was replaced with IDP, heat flow through the pipe walls was reduced dramatically. Using Eq 24 again, the effective conductivity of the composite pipe body (see Figure 13 ) was $0.41 \mathrm{~B} / \mathrm{hr}-\mathrm{ft}-\mathrm{F}$, compared to the value for steel of approximately 25. The "correction factor" used in the CDP test was essentially irrelevant here, because with IDP the first term in the denominator of Eq 24 is more than 10 times the sum of the second and third terms, and accurate calculation of the convective coefficients is not as critical as in the previous case.

In an actual IDP drillstring, however, the threaded connections (tool joints) between the individual pipes are not insulated. To evaluate the effect of these joints, an insulated pipe was cut in half, the male and female connections were screwed together, and this assembly was used as the test pipe. With this configuration, the overall effective conductivity of the IDP

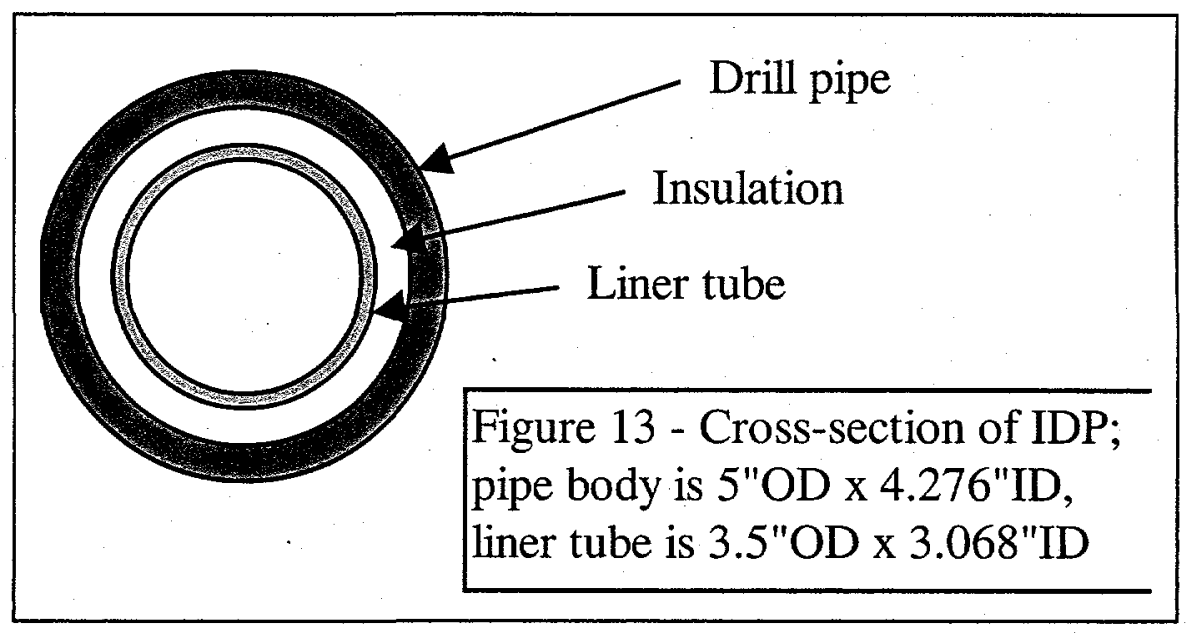
was $2.35 \mathrm{~B} / \mathrm{hr}-\mathrm{ft}-\mathrm{F}$, which was higher than calculations had suggested. The denominator of $\mathrm{Eq} 23$ is often taken to be the overall thermal resistance, $U$, of a tube with fluid flow inside and outside. That is, 


$$
U=\frac{1}{h_{i} r_{i}}+\frac{\ln \left(r_{o} / r_{i}\right)}{k_{\text {pipe }}}+\frac{1}{h_{o} r_{o}}
$$

Using $k_{\text {pipe }}=0.41 \mathrm{~B} / \mathrm{hr}-\mathrm{ft}-\mathrm{F}$ for the IDP body and 25 for the tool joint, calculated values of $U$ are $0.0640 \mathrm{hr}-\mathrm{ft}-\mathrm{F} / \mathrm{B}$ for the tool joint and 1.242 for the IDP. Because the total length of the test vessel was 25 feet, the effective length of the tool joint can be calculated from $\mathrm{Eq} 23$ as below:

$$
\dot{q}=63,000 \mathrm{~B} / \mathrm{hr}=2 \pi \Delta T_{a v g}\left[\frac{L_{i j}}{.064}+\frac{25-L_{i j}}{1.242}\right] \text {, where } L_{t j}=\text { effective tool joint }
$$
length.

Using measured values from the test series with the composite section, $L_{t j}=5.48$, which is considerably more than the tool joint's actual length of approximately 2 feet. This discrepancy may be caused by the reduced thickness of insulation where the ID of the drill pipe body necks down near the tool joint. The total $k$ value for a complete drillstring must also be corrected for the fact that an average joint of drill pipe is approximately 32' long, compared with the 25 ' test vessel. Adjusting conductivity to reflect this additional length, the final composite conductivity value, based on pipe OD of 5" and ID of 3.068", for a complete drillstring is $1.93 \mathrm{~B} / \mathrm{hr}-\mathrm{ft}-\mathrm{F}$.

Given this value, the effect of IDP in a high-temperature well can be evaluated. The curves below (Figure 14) show calculated drilling fluid temperatures in a 10,000' geothermal well with several different drillstring configurations (the left-hand side of each curve is temperature in the drill pipe and the right-hand side is in the annulus). In these calculations, the composite conductivity of the IDP is assumed to be $2 \mathrm{~B} / \mathrm{hr}-\mathrm{ft}-\mathrm{F}$. Because IDP is heavier and more expensive than conventional drill pipe, an important variable in designing the drillstring is the choice of whether to use IDP for the entire string. A partial IDP string would still have significant temperature advantages over $\mathrm{CDP}$, but would be more economical and would not require as large a rig. Although the figure is rather busy, the key results are summarized in the table below.

Table 1 - Summary of temperatures with various IDP configurations

\begin{tabular}{|l|c|c|c|c|c|}
\hline & All CDP & All IDP & $\begin{array}{c}\text { 4K' of IDP } \\
\text { @ top }\end{array}$ & $\begin{array}{c}\text { 4K' of IDP } \\
\text { @ bottom }\end{array}$ & $\begin{array}{c}\text { 4K' of IDP } \\
\text { in middle }\end{array}$ \\
\hline Returns temp., F & 163 & 196 & 182 & 170 & 175 \\
\hline BH fluid temp., F & 401 & 165 & 232 & 278 & 250 \\
\hline Max fluid temp., F & 406 & 215 & 244 & 306 & 261 \\
\hline
\end{tabular}

These calculations are encouraging, because they indicate that, if only part of the drillstring is IDP, it is most advantageous to have it at the top. Because of weight and 
strength considerations, the heaviest drill pipe should go at the top of the string anyway, so this is consistent with that criterion. In brief, the use of only 4,000' of IDP in a 10,000' drillstring can lower bottom-hole and maximum fluid temperatures from over $400^{\circ} \mathrm{F}$ to under $250^{\circ} \mathrm{F}$, which is a critical difference for many types of tools which use downhole electronics.

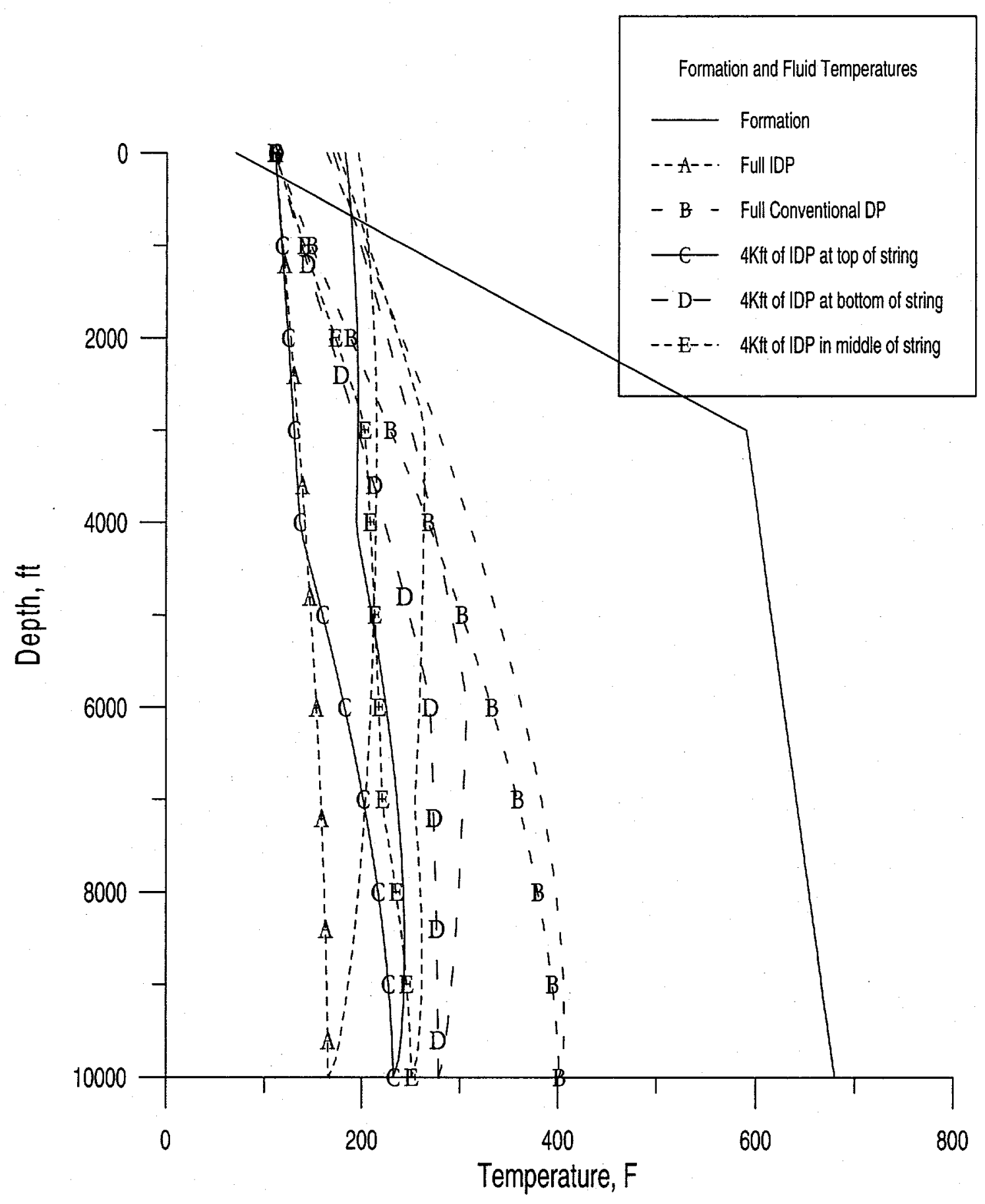

Figure 14 -- Drilling fluid temperatures with different IDP configurations 


\section{Field Test}

After encouraging results from analysis, laboratory testing, and field trials of 3 prototype joints of pipe, Drill Cool Systems fabricated a string (approximately 5500') of IDP to be used in actual drilling. This section describes a field test with this pipe.

Test Plan and Configuration: The test was done in an Imperial Valley well that had the undisturbed temperature profile shown in Figure 15 (temperature profiles in the well before the CDP and IDP tests are also shown.) Summary test plan was to circulate first through the CDP at two different flow rates, then pull out of the hole, wait for it to return to approximately the same beginning temperature profile as for the CDP, run in the hole with IDP, and circulate through the IDP at the same two flow rates as before. Another important objective of the test was to collect data for validation of GEOTEMP2, the software used since the beginning of the project to calculate effects of using IDP. At the time of the test, the well had casing/liner set to approximately 4100' but had not had the plug drilled out (i.e., there was no open hole, and no possibility of lost circulation.)

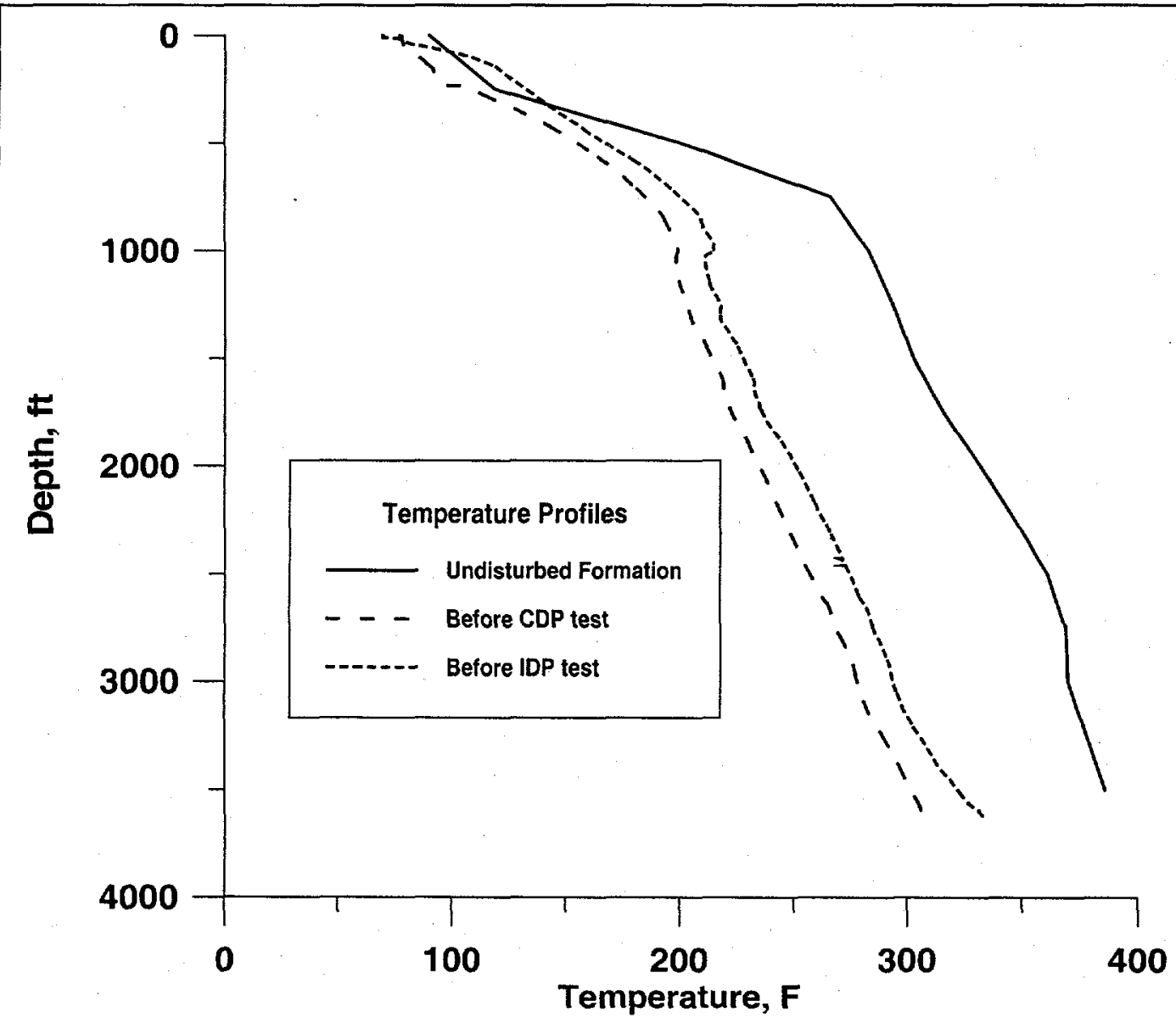

Figure 15 -- Temperature profiles before starting tests 
Temperature was measured before and after each test with Sandia's resistance temperature tool and logging truck, and was measured during circulation with fiber-optic sensors both inside the drill pipe and strapped to the outside of the drill pipe. Other test parameters measured at the surface were flow rate, fluid temperature into the mud pumps, fluid temperature out of the flow line, and standpipe pressure while pumping. The optical fibers were encased and protected by capillary tubing, and the capillary tubing inside the drill pipe was also used to suspend a Sandia pressure/temperature memory tool that stored bottom-hole data for retrieval after each test.

Test Results: About 34 hours after the last drilling activity in the hole (cleaning out cement after liner was cemented and turning hole over from mud to water) a temperature $\log$ of the hole was done and the conventional (4-1/2", $16.6 \mathrm{lb} / \mathrm{ft}$ ) drill pipe was run in to 3600 feet depth. The pipe did not go all the way to the bottom of the liner because two $4000^{\prime}$ pieces of optical fiber were not available. Circulation was begun at $300 \mathrm{gpm}$ until one wellbore volume was displaced and then reduced to $150 \mathrm{gpm}$. After circulating at this rate for 2.5 hours, the flow rate was increased to $500 \mathrm{gpm}$ for 2.8 hours. Results of this test are shown in Figure 16. This figure also shows a comparison between actual

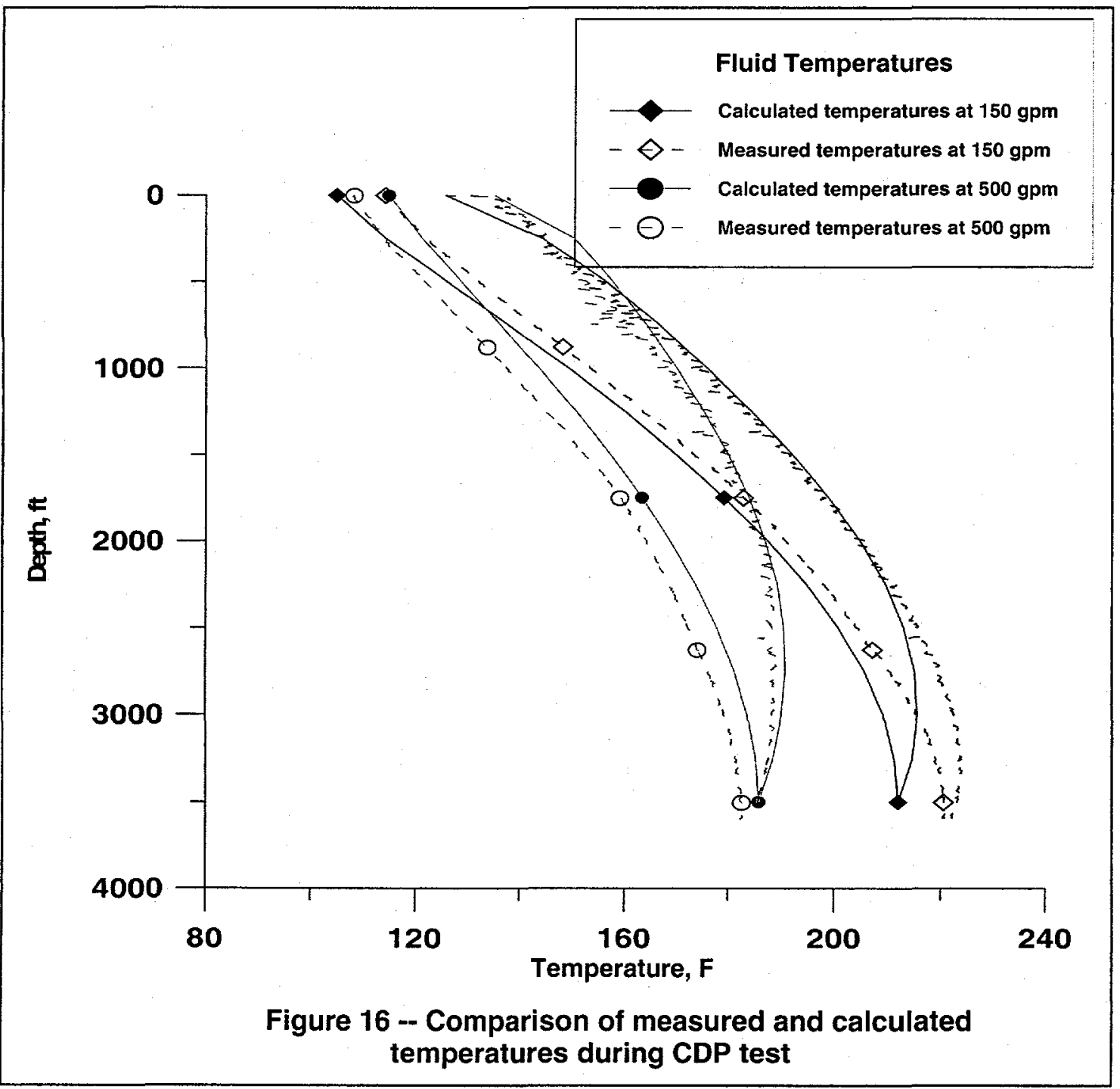


temperatures measured by the fiber-optic sensors and predicted values calculated by GEOTEMP2; this agreement is generally good.

Following this series of circulations, the CDP was pulled out and logs were taken to verify temperature recovery. After the wellbore temperature came back to approximately the same profile as before the CDP test, the IDP was run into the hole. The same test procedure as for the CDP was followed, although circulation was not maintained for as long a time because temperature variation was less with the IDP.

When beginning circulation in IDP at $150 \mathrm{gpm}$, the slug of hot water at the bottom of the hole moved up the annulus without the cooling effect normally contributed by the cool down-going fluid in the drill pipe. This meant that the much higher return temperatures caused some of the annular flow to flash to steam before temperatures stabilized. With the optical-fiber temperature profile measured in the annulus, however, it was possible to see the "bubble" of hot fluid moving up the annulus in real time, so that the driller could be aware of approaching boiling-point water. A time-lapse snapshot of annular temperatures is shown in Figure 17. If a drilling situation dictates that excess return

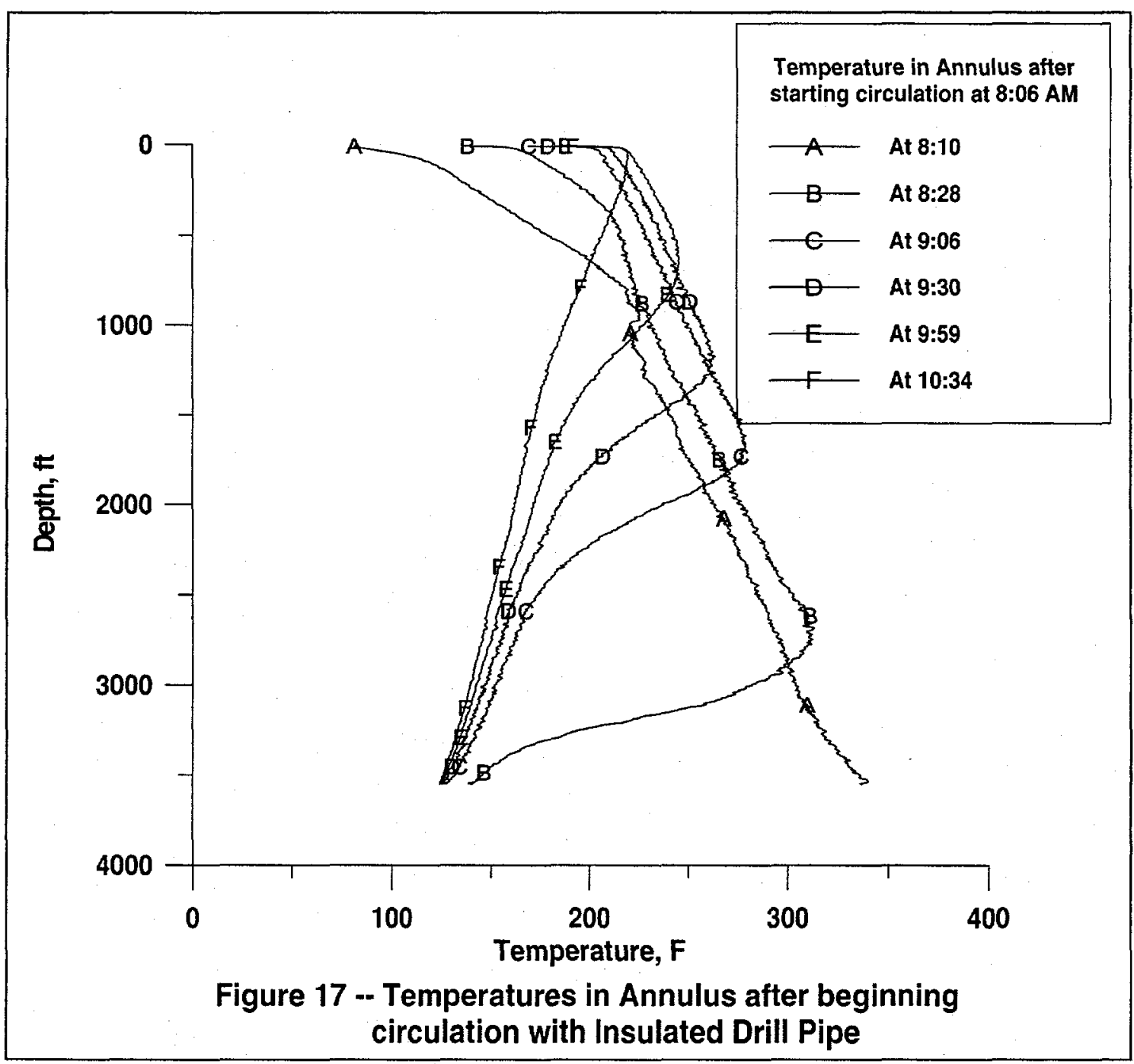

Insulated drill pipe - page 24 
temperatures after resuming circulation are not acceptable, a few stands of conventional drill pipe could be placed at the top of the drill string to cool the returns as they near the surface; the CDP could then be quickly removed and replaced with IDP for drilling.

The critical aspect of performance, however, is comparison of temperature with CDP and IDP at the same flow rate, having started at roughly the same wellbore temperature profile and circulated for comparable times. This is shown in Figure 18. After

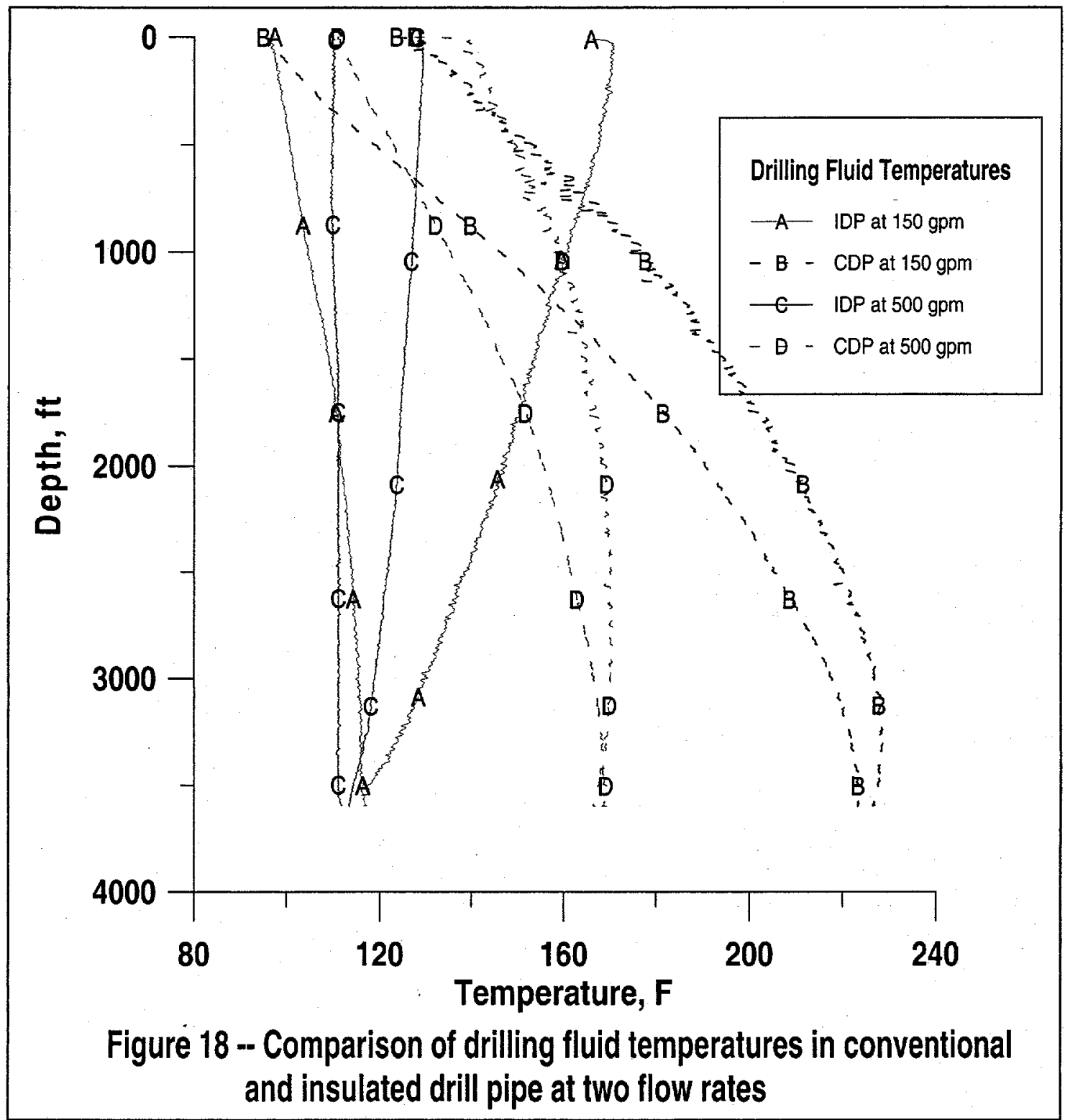

approximately one hour of circulation (one hour after reaching flow conditions without flashing returns), bottom-hole temperature is $224^{\circ} \mathrm{F}$ with CDP compared to $112^{\circ} \mathrm{F}$ with IDP at 150 -gpm flow rate, which is similar to flow rates used with downhole motors. This bottom-hole temperature is that which would be seen by downhole motors, steering tools, or measurement-while-drilling (MWD) instrumentation - even in this relatively cool well the temperature reduction is substantial. The relatively high return temperature 
for IDP at $150 \mathrm{gpm}$ (Figure 18) is a function of the short circulation time - in another hour of circulation, return temperature had dropped approximately $20^{\circ} \mathrm{F}$.

It is important to note that the bottom-hole cannot be effectively cooled by only lowering the mud inflow temperature; in the (calculated) case of CDP at $150 \mathrm{gpm}$ illustrated by Figure 16 , for example, lowering the inflow temperature by $20^{\circ} \mathrm{F}$ would only lower the bottom-hole temperature by $5.8^{\mathrm{O}} \mathrm{F}$.

Hydraulics: Because the IDP has a smaller average ID than the CDP (3.068" constant versus 3.826 " pipe with 2.812 " tool joints), there is a greater pressure drop through the IDP at equivalent flow rates. Frictional pressure loss can be measured by combining standpipe and bottom-hole pressures with static head of water at the appropriate temperature. At $500 \mathrm{gpm}$, pressure drops were $0.204 \mathrm{psi} / \mathrm{ft}$ in the IDP and $0.156 \mathrm{psi} / \mathrm{ft}$ in the CDP. This difference is less than might be expected from consideration of the diameters, but the tool-joint diameter reduction apparently has a substantial effect on pressure drop in the 4-1/2" drill pipe.

Extrapolation of results: Based on the test results and on generally good agreement between the GEOTEMP2 model and actual temperatures, we can extrapolate predictions of IDP performance in deeper, hotter wells. One of the major considerations in using insulated pipe for a deep well is its greater weight (approximately $33 \mathrm{lb} / \mathrm{ft}$ ). Because of the weight and expense, it may be cost-effective for only part of the drill string to be IDP, and it is useful to know where in the string the IDP should be placed, as discussed earlier and shown in Figure 14.

An alternative case with the same surface and bottom-hole temperatures, but with the high thermal gradient deeper in the well (break point in the bi-linear temperature profile is $400^{\circ} \mathrm{F}$ at $7000^{\prime}$ ), shows that position of the IDP is not as important and IDP does not change performance as much in this case. This is reasonable because the fluid is exposed to a lower average temperature during circulation. A summary of these results is shown below (compare with Table 1).

Table 2 - Summary of temperatures with various configurations of IDP

\begin{tabular}{|l|c|c|c|c|c|}
\hline & All CDP & All IDP & $\begin{array}{c}\text { 4K' of IDP } \\
\text { @ top }\end{array}$ & $\begin{array}{c}\text { 4K' of IDP } \\
\text { @ bottom }\end{array}$ & $\begin{array}{c}\text { 4K' of IDP } \\
\text { in middle }\end{array}$ \\
\hline Returns temp., F & 136 & 154 & 146 & 140 & 142 \\
\hline BH fluid temp., F & 290 & 146 & 196 & 203 & 192 \\
\hline Max fluid temp., F & 297 & 177 & 205 & 225 & 206 \\
\hline
\end{tabular}

Summary: Field test results are consistent with earlier analyses and laboratory tests, all of which support the conclusion that insulated drill pipe can have a very significant effect on circulating fluid temperatures. This will enable the use of downhole motors and 
steering tools in hot wells, and will reduce corrosion, deterioration of drilling fluids, and heat-induced failures in other downhole components.

\section{Conclusions}

Given that there is agreement on the benefits of cooler drilling fluid, this project has had three major questions to answer: Does IDP actually perform as hoped and expected? Can we analyze and predict the performance of IDP in realistic drilling situations? What is the best way to fabricate the insulated drill pipe? Answers, to the best current knowledge, follow.

Performance: Two aspects of performance - mechanical and thermal - must be considered. The mechanical analysis and pressure test described in Section III indicate that IDP will be suitable for drilling 15,000' wells in its present configuration and can go even deeper if the drill string is only partially IDP. Hoop strength in the liner tube might be improved with better compaction of the insulation material, but this is discussed in more detail below. Even though the axial, hoop, and bending stresses appear reasonable, the principal remaining mechanical uncertainty is fatigue behavior. A statistically valid indication of this will probably have to come from field use. Experience with the prototype joints in drilling one well and working over another has so far revealed no problems.

Thermal performance has been good. Conductivity of the insulated pipe body has been very near what was calculated, and the field test indicated that effective conductivity of the entire string is reasonably well understood. Many of the potential applications for IDP are in deep gas wells or in geothermal wells that are deeper than is now common. A valuable data point would be an IDP test in a deeper hole, which would illuminate thermal, mechanical, and hydraulic performance in that environment.

Analysis and prediction: As noted above, calculated effective conductivity of the pipe body is very near measured values, so the effect of changing thickness or type of insulation can be modeled with confidence. Predicting performance of IDP in a well is less certain, however, even though results from the field test described in Section V were encouraging.

A computer code, or wellbore simulator, called GEOTEMP2 has been used for all the modeling done in this project. GEOTEMP was originally written by an outside company under contract to Sandia and was later updated in-house as GEOTEMP2. It is a finiteelement program that calculates vertical and radial conduction in the rock, casing, and cement; conduction through the drill pipe; and convection at the wellbore wall and inside and outside the drill pipe. In comparison with actual data and with other wellbore simulators, GEOTEMP2 gives generally good agreement, but there are certain limitations in its use: it will not accept a change in casing diameter (i.e., it will not model a liner); it does not handle aerated mud well; calculated return temperatures are lower than indicated by field experience; and the temperature information required for the model is often 
unavailable in the field. In spite of this, the code is a useful tool to evaluate the effect of changes in IDP design, well configuration, or drilling conditions.

Pipe fabrication: In considering the general concept of insulated drill pipe, there are three basic approaches: single-wall tube with insulation coating on the inside; single-wall tube with insulation on the outside; and double-wall tube with insulation in the annulus, or volume, between the tubes. Advantages and disadvantages of each method are summarized below.

\begin{tabular}{|l|l|l|}
\hline \multicolumn{1}{|l|}{$\begin{array}{c}\text { Table 3- Fabrication methods for IDP } \\
\text { method }\end{array}$} & \multicolumn{1}{|c|}{ Advantages } & \multicolumn{1}{c|}{ Disadvantages } \\
\hline $\begin{array}{l}\text { Single-wall, } \\
\text { insulation inside }\end{array}$ & $\begin{array}{l}\text { light weight; insulation } \\
\text { protected from abrasion wear } \\
\text { and impact with casing or } \\
\text { wellbore; minimum erosion } \\
\text { from cuttings; could insulate } \\
\text { tool joints }\end{array}$ & $\begin{array}{l}\text { failed insulation could plug bit or } \\
\text { downhole motor; difficult to } \\
\text { install, repair or replace } \\
\text { insulation; requires tough, strong } \\
\text { insulation }\end{array}$ \\
\hline $\begin{array}{l}\text { Single-wall, } \\
\text { insulation } \\
\text { outside }\end{array}$ & $\begin{array}{l}\text { light weight; insulation easy to } \\
\text { apply; insulation failure would } \\
\text { not have serious effect on } \\
\text { circulation }\end{array}$ & $\begin{array}{l}\text { insulation vulnerable to erosion } \\
\text { and impact; probably could not } \\
\text { insulate tool joints or pipe- } \\
\text { handling areas of pipe body; } \\
\text { requires tough, strong insulation }\end{array}$ \\
\hline Double-wall & $\begin{array}{l}\text { reliable protection for } \\
\text { insulation; no strength (except } \\
\text { compressive) or toughness } \\
\text { requirement on insulation; } \\
\text { insulation material development } \\
\text { not required }\end{array}$ & $\begin{array}{l}\text { pipe is heavy; fabrication and } \\
\text { material are expensive; reduced } \\
\text { inside diameter affects hydraulics } \\
\text { b }\end{array}$ \\
\hline
\end{tabular}

Although there are clear advantages for a single-wall tube (most likely with insulation inside), pursuit of that goal has been deferred until the value of IDP has been demonstrated to and accepted by industry.

\section{Recommendations}

The IDP development program described above has led to several recommendations for changes that should improve the performance and acceptance of this product in the field.

- Develop insulation material for single-wall pipe - As shown in Table 3, there are significant advantages to single-wall pipe with an insulating coating. This is not an easy task, however, because the coating must not only have low thermal conductivity, but must be tough enough to resist cracking, must be strongly bonded to the pipe wall, must resist abrasion from particles in the drilling fluid, and should have thermal expansion relatively near steel to prevent inter-laminar 
stresses when the pipe heats up. Nevertheless, it is a goal worth pursuing and should probably be the highest priority among these recommendations.

- Improve insulation compaction for double-wall pipe - Because the liner tube in IDP partially depends on the insulation for structural support, better compaction of the insulating material, or possibly adding a liquid resin to the granular insulation, would give better support.

- Run longer IDP string - The field test used a relatively short (3600') string of IDP. Even though the wellbore simulator showed good agreement between measured and calculated results, field experience with longer strings (or mixed IDP/CDP strings) would improve confidence in IDP.

- Perform field tests in hotter, deeper wells with different temperature profile - The field test was representative of some types of geothermal operations, but did not reflect temperatures as high as those commonly encountered in drilling. The temperature profile was also more typical of geothermal wells than of deep, hot gas wells, which are expected to be one of the major applications for this technology.

- Improve wellbore simulator - Although the GEOTEMP2 simulator used for the calculations in this report gives good agreement with field data, it has a number of shortcomings (noted on p. 27) in operation. An improved simulator that addresses most of these problems, and has a Windows-like graphical user interface, is under development by a contractor but functional results are not yet available.

\section{References}

1. L. A. Mondy, L. E. Duda; "Advanced Wellbore Thermal Simulator GEOTEMP2 User Manual"; Sandia Report SAND84-0857, Sandia National Laboratories, Albuquerque, NM 87185-1033; November 1984.

2. J. T. Finger; Drilling Fluid Temperatures in a Magma-Penetrating Wellbore; Geothermal Resources Council TRANSACTIONS, Vol. 10, September 1986.

3. R. A. Crewdsen, W. F. Martin Jr., D. L. Taylor, and K. Bakhtar; MAGMA ENERGY: An evaluation of the Technology and Economics of Extracting Energy from Magma Resources for Electric Power Generation; Final report for the California Energy Commission and Mono County, California; submitted by Mine Development and Engineering Co., Bakersfield, California; March 1991.

4. R. C. Dykhuizen and C. E. Sisson; Sandia National Laboratories memo to J. T. Finger; January 1989. 
Mike Akins

Chevron Petroleum Technology Co.

PO Box 4450

Houston TX 77210

Bill Calhoun

Chevron Petroleum Technology Co.

2202 Oil Center Court

Houston, TX 77073

Louis E. Capuano, Jr.

ThermaSource, Inc.

PO Box 1236

Santa Rosa, CA 95402

(10) Tom Champness

Drill-Cool Systems

627 Williams Street

Bakersfield, CA 93305

Ted Clutter

Executive Director

Geothermal Resources Council

PO Box 1350

Davis, CA 95617

Gary Collins

Marathon Oil Company

PO Box 3128

Houston, TX 77253-3128

Jim Combs

Geo-Hills Associates

2395 Catamaran Drive

Reno, NV 89509-5731

Dr. George Cooper

UC-Berkeley

595 Evans Hall

Berkeley, CA 94720

J. David Dowell

Texaco - Upstream Technology

Drilling and Completions Technology

3901 Briarpark

Houston, TX 77042
Phil Frink

Blade Energy Partners

1415 Halsey Way, Suite 300

Carrollton, TX 75007

Steve Furry

Unocal

1300 North Dutton Avenue

Santa Rosa, CA 95401-4687

Sabodh K. Garg

Manager, Resource Technology

Maxwell Technologies, Inc.

PO Box 23558

San Diego, CA 92123-2355

Marvin Gearhart

RBI-Gearhart

7601 Will Rogers Blvd.

Ft. Worth TX 76140-0540

Dave Glowka

ENP Capital Resources, Inc.

811 Sussex Drive

Austin, TX 78745

Colin Goranson

1498 Aqua Vista Road

Richmond, CA 94805

Jerry Hamblin

Unocal

1300 North Dutton Avenue

Santa Rosa, CA 95401-4687

Gerald W. Huttrer

Geothermal Management Company

P O Box 2425

Frisco, CO 80443

Allan Jelacic

Office of Geothermal \& Wind

Technologies

U.S. Department of Energy, EE-12

1000 Independence Ave. SW

Washington, DC 20585 
Ray LaSala

Office of Geothermal \& Wind

Technologies

U.S. Department of Energy, EE-12

1000 Independence Ave. SW

Washington, DC 20585

Bill Livesay

Livesay Consultants

126 Countrywood Lane

Encinitas, CA 92024-3109

James W. Lovekin

GeoThermex, Inc.

Manager of Field Operations

5221 Central Avenue, Suite 201

Richmond, CA 94804-5829

Dr. William C. Maurer, President

Maurer Engineering, Inc.

2916 West T.C. Jester

Houston, TX 77018

Tsvi Meidav

Trans-Pacific Geothermal Corporation

111 Broadway, Suite 300

Oakland, CA 94607

Nic Nickels

Baker-Hughes INTEQ

2050 West Steele Lane, Suite C-1

Santa Rosa, CA 95403

Marshall Pardey

QD Tech, Inc.

4558 South Kayland Circle

Salt Lake City, UT 84117

Michael L. Payne, P.E., Ph.D.

ARCO E \& P Technology

Drilling and Completion Technology

2300 West Plano Parkway

Plano, TX 75075-8499

Gene Polk

Baroid Drilling Fluids, Inc.

2220 First St NW

Albuquerque, NM 87107
Gene Pollard

Ocean Drilling Program

1000 Discovery Drive

College Station TX 77840

Eddie Pruett

Pruett Industries

8915 Rosedale Highway

Bakersfield, CA 93312

Robert P. Radtke, President

Technology International, Inc.

2103 River Falls Drive

Kingwood, TX 77339-3154

Bill Rickard

Resource Group

40201 Sagewood Drive

Palm Desert, CA 92260

Dr. Leon Robinson

826 Heathcliff Court

Houston, TX 77024

John C. Rowley

Pajarito Enterprises Consulting Services

3 Jemez Lane

Los Alamos, NM 87544

Dan A. Sanchez

US Department of Energy

Albuquerque Office

DOE/AL

Paul Schilte

Shell International Exploration and

Production

Research and Technical Services (RTS)

Volmerlaan 8, $2280 \mathrm{AB}$

RIJSWIJK, The Netherlands

Gary L. Smith

Conoco, Inc.

Leader, Drilling Technology

Offshore, 1006

P O Box 2197

Houston, TX 77252-2197 
Paul Spielman

Coso Operating Co.

900 N. Heritage, Building D

Ridgecrest, CA 93555

Cheryl L. Stark

BP Amoco

P.O. Box 3092 - 19.194W1

Houston, TX 77253-3092

Bob Swanson

Unocal

1300 North Dutton Avenue

Santa Rosa, CA 95401-4687

Michael E. Utt, P.E.

Technology \& Operations Support

Unocal Corporation

14141 Southwest Freeway

Sugar Land, TX 77478-3435

Tommy M. Warren

Director, Research \& Development

TESCO Drilling Technology

Rt. 1, Box 130-10

Coweta, OK 74429

1 MS 0741 S. G. Varnado 6200

1 MS 1033 M. R. Prairie 6211

10 MS 1033 J. T. Finger $\quad 6211$

1 MS 1033 R. D. Jacobson 6211

1 MS 1033 G. L. Whitlow 6211

1 MS 1033 J. A. Henfling 6211

1 MS 1033 J. L. Wise 6211

1 MS 1033 A. R. Sattler 6113

2 MS 0899 Tech Library 9616

1 MS 0612 Review \& Approval Desk for DOE/OSTI 9612

1 . MS 9018 Cent. Tech. Files 8940-2

1 MS 0161 Patent \& Licensing

Office

11500 